\title{
Advanced Co304-CuO nano-composite based electrocatalyst for efficient hydrogen evolution reaction in alkaline media
}

Aneela Tahira, Zafar Hussain Ibupoto, Magnus Willander and Omer Nur

The self-archived postprint version of this journal article is available at Linköping University Institutional Repository (DiVA):

http://urn.kb.se/resolve?urn=urn:nbn:se:liu:diva-162348

N.B.: When citing this work, cite the original publication.

Tahira, A., Ibupoto, Z. H., Willander, M., Nur, O., (2019), Advanced Co3O4-CuO nano-composite based electrocatalyst for efficient hydrogen evolution reaction in alkaline media, International journal of hydrogen energy, 44(48), 26148-26157. https://doi.org/10.1016/j.ijhydene.2019.08.120

Original publication available at:

https://doi.org/10.1016/j.ijhydene.2019.08.120

Copyright: Elsevier

http://www.elsevier.com/

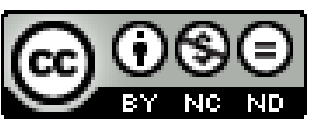




\title{
Advanced $\mathrm{Co}_{3} \mathrm{O}_{4}-\mathrm{CuO}$ nano-composite based electrocatalyst for efficient hydrogen evolution reaction in alkaline media
}

Aneela Tahira ${ }^{\mathrm{a}}$, Zafar Hussain Ibupoto ${ }^{\mathrm{b}}$, Magnus Willander ${ }^{\mathrm{a}}$, Omer Nur ${ }^{\mathrm{a}}$

${ }^{a}$ Department of Science and Technology, Campus Norrkoping, Linkoping University, SE-60174 Norrkoping, Sweden

${ }^{b}$ Dr. M.A Kazi Institute of Chemistry University of Sindh Jamshoro, 76080, Sindh Pakistan

Corresponding author: Zafar Hussain Ibupoto

Email address: zaffar.ibhupoto@usindh.edu.pk

\begin{abstract}
In this study, we incorporate a copper impurity into $\left(\mathrm{Co}_{3} \mathrm{O}_{4}\right)$ nanowires precursor that turn them into an active catalyst for the hydrogen evolution reaction in $1 \mathrm{M} \mathrm{KOH}$. The XRD and XPS results are in good agreement and confirmed the formation of $\mathrm{Co}_{3} \mathrm{O}_{4}-\mathrm{CuO}$ nano- composite by wet chemical method. To date, the performance of hydrogen evolution reaction in alkaline for the composite catalyst is comparable or superior to cobalt oxide based HER electro-catalysts. The HER catalyst exhibits the lowest Tafel slope of $65 \mathrm{mVdec}^{-1}$ for the cobalt-based catalysts in alkaline media. A current density of $10 \mathrm{~mA} / \mathrm{cm}^{2}$ is achieved at a potential of $0.288 \mathrm{~V}$ vs reversible hydrogen electrode (RHE). The mixed transition metal oxide $\mathrm{Co}_{3} \mathrm{O}_{4}-\mathrm{CuO}$ based HER electrocatalyst is highly stable and durable. The EIS results demonstrates that HER is highly favorable on the $\mathrm{Co}_{3} \mathrm{O}_{4}-\mathrm{CuO}$ due to the relatively small charge transfer resistance $(173.20 \mathrm{Ohm})$ and higher capacitance values $(1.97 \mathrm{mF})$.
\end{abstract}

Keywords. Composite metal oxide, electro-catalyst, hydrogen evolution reaction 


\section{Introduction}

Hydrogen being a neat and the potential renewable energy resource has been considered as a promising alternative to replace the fossil fuels [1-4]. The electrochemical water splitting into hydrogen and oxygen in an electrolyzer is the most exciting technology to produce high purity molecular hydrogen [5-10]. Despite the advantageous features of water electrolysis for hydrogen

production, still, it is limited by the poor performance of non-precious catalysts and high scarcity of the noble catalysts $[2,11]$. To date, platinum $(\mathrm{Pt})$ is only up to the mark catalyst for the hydrogen evolution reaction (HER), but its high cost and low abundance do not allow it for the widespread applications [13]. To replace Pt, transition metal-based compounds including metal sulfides [1318], selenides [19,20], phosphides [21-23], nitrides [24,25], carbides [26,27], oxides [28], and metal alloys $[29,30]$ have been employed due to their low cost and earth abundant nature. Also, different recent works on the hydrogen production are reported recently [31-36], Moreover, the industrial catalysts such as nickel $(\mathrm{Ni})$ and stainless steel are also frequently used as water reduction and oxidation in alkaline media [37]. It is proved that nickel is not a perfect HER catalyst because of its high overpotential approximately and large Tafel slope values [37,38]. Importantly, nickel is carcinogenic substance reported elsewhere. Also, a wide range of active and stable nonnoble metal based HER catalysts in alkaline media are reported [39-46]. In order to achieve performance like Pt from non-precious catalysts is still at an early stage since a single nonprecious catalyst is lacking either due to the absence of high activity or stability issues.

Since few decades, transition metal oxides are found promising oxygen evolution reaction OER catalysts in alkaline solution [51]. Recently, transition metal oxides are combined with noble metals to enhance the HER activity in alkaline media. Heterostructured electrocatalyst can be designed at the nano- or micro levels [52-57]. However, pristine transition metal oxides are known as poor catalysts for HER due to their high unsuitable hydrogen adsorption energy. Moreover, perovskite oxide shows a remarkable effectiveness for HER electrocatalyst that is active and stable in alkaline media. The most recent achievements of perovskite oxide for the electrocatalysis enhanced the functionality and provide a possible future research direction for double perovskites [53]. But the metal oxides based on earth abundant materials are of great interest to materialize for large scale and practical applications, thus more investigations are needed to improve their functional properties. In the present research hypothesis, a small incorporation of the copper 
concentration into the $\mathrm{Co}_{3} \mathrm{O}_{4}$ nanowires precursor brought a significant enhancement in the catalytic activity due to the possible decreases in the hydrogen adsorption energy and an enhanced conductivity.

Herein, we report for the first time a new class of composite namely $\mathrm{Co}_{3} \mathrm{O}_{4}-\mathrm{CuO}$ nanostructure exhibiting an excellent HER activity and good stability in alkaline media. The structural and composition characterization are carried out by various analytical techniques such as SEM, EDS, XRD, and XPS. The composite catalyst is mainly composed of $\mathrm{Co}_{3} \mathrm{O}_{4}$ and $\mathrm{CuO}$ and no other impurity is detected. This electro-catalyst achieved a current density of $10 \mathrm{~mA} / \mathrm{cm}^{2}$ at a potential of $0.288 \mathrm{~V}$ vs RHE in alkaline media.

\section{Materials and Methods}

Cobalt chloride hexahydrate, copper chloride dihydrate, $20 \% \mathrm{Pt} / \mathrm{C}, 85 \%$ potassium hydroxide $\mathrm{KOH}$, fluorine-doped tin oxide FTO and urea of $99.5 \%$ purity were purchased from Sigma Aldrich Stockholm, Sweden. In a typical synthesis, 2.37 grams of cobalt chloride hexahydrate, 1.20 grams of copper chloride dihydrate and 0.6 grams of urea were dissolved in $100 \mathrm{~mL}$ of the deionized water. The solution was stirred for 20 minutes until a homogeneous solution is obtained. Then FTO substrate was sonicated in acetone and washed several times with the deionized water. The cleaned FTO substrates were coated with a colloidal seed solution of cobalt chloride by a dip coating method. The dip coating was done gently and the FTO seed coated substrates were annealed at $130{ }^{\circ} \mathrm{C}$ for 25 minutes in order to firm binding of seed particles. The seed layered FTO substrates were vertically dipped into the growth solution by exposing the seed-coated FTO facets towards the growth solution. Then samples in the growth solution were covered with the aluminum foil and kept in a preheated electric oven for 5 hours at $90{ }^{\circ} \mathrm{C}$. Afterward, the samples were taken out and washed several times with the deionized in order to remove unwanted particles from the surface of the nanostructured material grown on the FTO substrates. The samples were annealed at $500{ }^{\circ} \mathrm{C}$ for 4 hours in order to convert the hydroxide phase into composite oxide nanostructures. The same method was used for the collection of powder of mixed transition metal oxide nanostructures. Pristine $\mathrm{Co}_{3} \mathrm{O}_{4}$ nanostructures were also prepared by the same method without the addition of copper salt. The synthesis of pristine $\mathrm{CuO}$ nanostructures was carried out by the mixing of copper chloride and urea in $100 \mathrm{~mL}$ of the deionized water. The FTO substrate was seeded with $\mathrm{CuO}$ nanoparticles and was hanged vertically in the precursor's the solution at $90{ }^{\circ} \mathrm{C}$ for 5 hours. 
Then a black layer on the FTO was found and it indicated the presence of $\mathrm{CuO}$. Likewise, $\mathrm{CuO}$ nano-powder was collected by filtration. The morphological features of the nanostructured material were investigated by scanning electron microscopy (SEM) using a Hitachi model H800 at an accelerating voltage of $3 \mathrm{kV}$, while Philips powder X-ray diffraction technique was used to determine the crystalline structure, phase, and purity, and energy dispersive spectroscopy (EDS) technique was used for composition analysis of the as-prepared samples. The electrochemical characterization was performed in $1 \mathrm{M} \mathrm{KOH}$ at room temperature. A catalyst ink of various materials was prepared by dispersing $10 \mathrm{mg}$ powder of each catalyst into $2.5 \mathrm{~mL}$ of the deionized water and $0.5 \mathrm{~mL}$ of $5 \%$ Nafion. Prior to the surface modification, the cleaning of glassy carbon electrode (GCE) was done through polishing with $0.05 \mu \mathrm{m}$ alumina powder and then rubbed with silica and washed several times with the deionized water. The deposition of $10 \mu \mathrm{L}$ of the catalyst ink on the clean GCE was done via drop casting method. The modified GCE as working electrode, a platinum wire as a counter electrode and silver-silver chloride (Ag/AgCl) saturated with $3 \mathrm{M} \mathrm{KCl}$ as a reference electrode was configured into three electrode electrochemical cells. The reference electrode $\mathrm{Ag} / \mathrm{AgCl}$ was calibrated using 15\% hydrogen gas in Argon then bubbled into the $1 \mathrm{M} \mathrm{KOH}$ electrolyte. The counter Pt electrode and reference electrodes were connected with the two probe multi-meter and potential was recorded. Linear sweep voltammetry and cyclic voltammetry were used to evaluate the catalytic response and durability of the catalyst. The chronopotentiometry was uses to investigate the stability of electrocatalyst at a constant current density of $10 \mathrm{~mA} / \mathrm{cm}^{2}$. Electrochemical impedance spectroscopy was conducted for the investigation of the HER kinetics in a frequency range of $100 \mathrm{kHz}$ to $0.1 \mathrm{~Hz}$ at an amplitude of 10 $\mathrm{mV}$ and onset potential of $-0.3 \mathrm{~V}$ vs RHE (reversible hydrogen electrode) in $1 \mathrm{M} \mathrm{KOH}$ electrolyte. All the potentials are reported into RHE without iR drop. All the experiments were performed at room temperature.

\section{Results and Discussion}

\subsection{The structural and compositional characterization of various nanostructured materials}

Scanning electron microscopy was employed to explore the morphological features of various nanostructured materials. Figure $1 \mathrm{a}, \mathrm{b}$ shows the leaf-like features of the $\mathrm{CuO}$ nanostructures at different magnifications. The thickness of each leaf is a few hundred nm and they are uniform in distribution on the FTO glass substrate. Figure 1c, d shows the $\mathrm{Co}_{3} \mathrm{O}_{4}$ nanowires at different 
magnifications, the length of each nanowire was few microns, and the average diameter of each nanowire is approximately $200 \mathrm{~nm}$ to $500 \mathrm{~nm}$. But the nanowires are not well oriented and randomly distributed on the FTO substrate as clearly seen from Figure 1c, d. Figure 1e, f shows the structural features of composite $\mathrm{Co}_{3} \mathrm{O}_{4}-\mathrm{CuO}$ and it exhibited a nanowire like structure. The top surface of the nanowire is very thin and sharp due to the incorporation of copper metal atoms into the cobalt oxide nanowire. The length of the nanowires is several microns and the average diameter is around $100 \mathrm{~nm}$ to $300 \mathrm{~nm}$. The SEM results of the mixed transition metal oxide are clearly indicating that the self-assembly of nanoparticles turned into a nanowire morphology. The sharpness of nanowire for the composite material has more surface area which provide more contact area with the electrolyte and thus it accelerates the HER kinetics. The SEM study was carried out on the composite catalyst after stability and durability experiment as shown in $\mathrm{S} 1$. It can be seen that composite catalyst has tendency to retain the morphology and a slight top surface of the nanowires is etched due to alkaline nature of the electrolyte. The elemental composition of each sample was investigated by the energy dispersive spectroscopy. The elemental mapping of the pristine $\mathrm{CuO}$ and $\mathrm{Co}_{3} \mathrm{O}_{4}$ was also carried out as shown in the supplementary data in Figures $\mathrm{S} 2$ and $\mathrm{S} 3$. In the $\mathrm{CuO}$ sample, the $\mathrm{Cu}$ and $\mathrm{O}$ are the main components derived from the $\mathrm{CuO}$ and in a sample of the $\mathrm{Co}_{3} \mathrm{O}_{4}$, $\mathrm{Co}$ and $\mathrm{O}$ are inherently visible. In both samples, $\mathrm{Sn}$ is involved from the FTO substrate. Figure 2a shows the elemental mapping of $\mathrm{Co}_{3} \mathrm{O}_{4}-\mathrm{CuO}$ samples and it indicates the uniform distribution of $\mathrm{Co}, \mathrm{O}$, and $\mathrm{Cu}$ in the nanowire morphology. The contribution of $\mathrm{Sn}$ is also visible, and it is coming from the FTO substrate. The relative amount of $\mathrm{Co}, \mathrm{O}$, and $\mathrm{Cu}$ is presented in the EDS spectrum as shown in Figure 2b. Importantly, the amount of $\mathrm{Co}$ and $\mathrm{Cu}$ in the composite material has shown significant role in the HER process and it opens the gate way for the development of functional catalysts based on the $\mathrm{Cu}-\mathrm{Co}$ systems.

The crystal structure of various nanostructured materials on the FTO substrate was confirmed by powder X-ray diffraction (XRD). Figure $3 \mathrm{a}-\mathrm{c}$ describe the diffraction patterns of the $\mathrm{CuO}$, $\mathrm{Co}_{3} \mathrm{O}_{4}$, and composite $\mathrm{Co}_{3} \mathrm{O}_{4}-\mathrm{CuO}$ at $2 \theta$ range of $10-80^{\circ}$. All the materials exhibit sharp peaks, which indicate their high crystalline quality. Four different diffraction patterns are also identified for the FTO substrate as shown in Figure 3a-c. The diffraction patterns of pure $\mathrm{CuO}$ are well matched to the standard JCPDS card no.96-900-8962 and the material exhibits monoclinic phase. The $\mathrm{Co}_{3} \mathrm{O}_{4}$ nanowire reflection peaks are in good agreement with the 
standard JCPDS card no.96-900-5890 and it has a cubic phase. The mixed transition metal oxide sample has shown well-resolved diffraction patterns for both $\mathrm{Co}_{3} \mathrm{O}_{4}$ and $\mathrm{CuO}$ and they are fully supported by the standard JCPDS cards of pristine $\mathrm{Co}_{3} \mathrm{O}_{4}$ and $\mathrm{CuO}$ cases. The incorporation of $\mathrm{CuO}$ into the $\mathrm{Co}_{3} \mathrm{O}_{4}$ nanowires has shown the suppression of intensity for the reflection peaks of cobalt oxide which might induce the defects in the crystal structure of composite materials, and they could be responsible for the favorable HER process. No other impurity was found in all the samples.

The XPS characterization was carried out on the composite $\mathrm{Co}_{3} \mathrm{O}_{4}-\mathrm{CuO}$ sample. The wide scan survey spectra confirm the presence of $\mathrm{Co}, \mathrm{Cu}$, and $\mathrm{O}$ in the sample as shown in Figure 4a. The Co2p XPS spectrum is shown in Figure $4 \mathrm{~b}$ that indicates the satellite peaks at the binding energies of $795.06 \mathrm{eV}$ and $779.68 \mathrm{eV}$ related to Co2p3/2, and Co2p1/2, respectively. The spinorbit energy difference between them is $15 \mathrm{eV}$ which is indexed to the $\mathrm{Co}^{2+}$ valence state [58]. Figure 4c shows two peaks at binding energies of $529.66 \mathrm{eV}$ which is the characteristic peak for the metal-oxygen bonds and another peak at $531.01 \mathrm{eV}$ that is attributed to the presence of surface oxygen vacancies $[59,60]$. Figure $4 \mathrm{~d}$ shows the oxidation states of the $\mathrm{Cu}$ investigated by the high-resolution $\mathrm{Cu} 2 \mathrm{p}$ spectrum that contains shake-up satellite peaks which confirms the typical features of $\mathrm{CuO}$ [61-64]. Further, the existence of $\mathrm{CuO}$ in the composite sample is verified by the binding energies of the $\mathrm{Cu} 2 \mathrm{p} 3 / 2$ and the $\mathrm{Cu} 2 \mathrm{p} 1 / 2$ measured at $933.66 \mathrm{eV}$ and $953.65 \mathrm{eV}$, respectively $[62,63,64,65-66]$. The XPS results revealed that the composite is successfully obtained and that it is completely in good agreement with the XRD results. Furthermore, XPS technique was used to investigate the composition of the pristine cobalt oxide and $\mathrm{CuO}$ as shown in $\mathrm{S} 4$ and it confirms the presence of $\mathrm{Co}, \mathrm{Cu}$ and $\mathrm{O}$ as main elements and no other element was detected. No, any other impurity was found in the sample during the XPS characterization. Based on the XPS results, it is confirmed that incorporation of $\mathrm{Cu}$ into the $\mathrm{Co}_{3} \mathrm{O}_{4}$ nanowires has tune its electronic properties, thus HER activity is strongly increased.

\subsection{HER activity of the newly developed composite $\mathrm{Co3O}_{4}-\mathrm{CuO}$ electro-catalyst}

HER activity of the $\mathrm{Co}_{3} \mathrm{O}_{4}-\mathrm{CuO}$ mixed transition metal oxide was evaluated in an alkaline solution. Various catalysts were deposited on the GCE and it was configured into the electrochemical cell as a working electrode. The performance of the mixed transition metal oxide was compared with that of the pristine $\mathrm{Co}_{3} \mathrm{O}_{4}$ and $\mathrm{CuO}$ and noble catalyst $20 \%$ 
$\mathrm{Pt} / \mathrm{C}$. Linear sweep voltammetry was used to record the HER polarization curves at a scan rate of $5 \mathrm{mV} / \mathrm{s}$. $\mathrm{CuO}$ is not active for HER due to its high over-potential, but the $\mathrm{Co}_{3} \mathrm{O}_{4}$ has shown poor HER activity. However, composite $\mathrm{Co}_{3} \mathrm{O}_{4}-\mathrm{CuO}$ has shown significant enhancement in the HER activity at the low potential that is close to the noble Pt/C catalyst as shown in Figure 5a. A current density of $10 \mathrm{~mA} / \mathrm{cm}^{2}$ is achieved at the potential of $0.288 \mathrm{~V}$ vs RHE which is very comparable to the recently reported $\mathrm{CoO}$ based catalysts [67].

The HER mechanism on the surface of the metal oxide proceeds through either VolmerHeyrovsky or Volmer-Tafel mechanism in alkaline media [68].

$*+\mathrm{H}_{2} \mathrm{O}+\mathrm{e}^{-} \rightleftharpoons \mathrm{H}^{*}+\mathrm{OH}^{-*}+\mathrm{H}_{2} \mathrm{O}+\mathrm{e}^{-} \rightleftharpoons \mathrm{H}^{*}+\mathrm{OH}^{-}$(Volmer reaction: Discharge step 1

$\mathrm{H} *+\mathrm{H}_{2} \mathrm{O}+\mathrm{e}-\rightleftharpoons \mathrm{H}_{2}+\mathrm{OH}^{-}$(Heyrovsky: Desorption step reaction 2

and $2 \mathrm{H}^{*} \rightleftharpoons \mathrm{H} 2$ Tafel: Recombination step, Here $*$ is the active site). 3

The Tafel slope values of 120, 40 and $30 \mathrm{mV} \mathrm{dec}^{-1}$ are associated to Volmer reaction, Heyrovsky reaction, and Tafel reaction, respectively.

It is proved that the transition metal oxides are not suitable catalysts for transforming the $\mathrm{H}^{*}$ to $\mathrm{H}_{2}$ due to strong $\mathrm{H}^{*}$ adsorption on the $\mathrm{O}$, but relatively weak $\mathrm{H}^{*}$ adsorption on metal ion [57, $53,54]$. However, they have demonstrated very well for the cleavage of $\mathrm{OH}-\mathrm{H}$ bond in the Volmer step [59, 62, 55, and 69]. Recently, a published work on CoO nanorods [67] has Tafel slope of $82 \mathrm{mVdec}^{-1}$. But the proposed catalyst based on composite $\mathrm{Co}_{3} \mathrm{O}_{4}-\mathrm{CuO}$ has smaller Tafel slope value of $65 \mathrm{mVdec}^{-1}$ as shown in Figure 5b. It follows that the Volmer-Heyrovsky mechanism further confirms that the desorption step (Heyrovsky reaction) is the ratedetermining step during the HER process. Similarly, the $\mathrm{Co}_{3} \mathrm{O}_{4}$ has shown Heyrovsky-Volmer mechanism and exhibited a Tafel slope of $94 \mathrm{mVdec}^{-1}$ which is comparable to that of reported work [67]. The Pt/C has Tafel slope of $49 \mathrm{mVdec}^{-1}$ and it follows the Volmer-Heyrovsky reaction mechanism. The Tafel slope of GCE and $\mathrm{CuO}$ are $328 \mathrm{mVdec}^{-1}$ and $243 \mathrm{mVdec}^{-1}$, respectively. These are very large in magnitude due to self-resistance offered by the material and the electrode $[70,71]$. Looking into the consideration of the SEM and the XRD results, it is obvious that the $\mathrm{Co}_{3} \mathrm{O}_{4}-\mathrm{CuO}$ has less intense reflections for cobalt oxide when compared to the pristine $\mathrm{Co}_{3} \mathrm{O}_{4}$. This suggests that crystal defects might enhance the HER activity and SEM study has also shown that nanowires of mixed metal oxide are thinner than the pristine cobalt 
oxide with large catalytic sites and surface area which are in great contact with the electrolyte and favors the active HER process. Additionally, the EDS study confirms that Co is replaced by copper in mixed transition metal oxide sample as shown in Figure $2 b$ and the presence of Co and $\mathrm{Cu}$ in the mixed transition metal oxide synergistically enhance the HER activity. It is true that the content of $\mathrm{Co}$ and $\mathrm{Cu}$ is low in the mixed sample as shown in Figure $2 \mathrm{~b}$ when compared to the amount of $\mathrm{Co}$ and $\mathrm{Cu}$ in the pristine samples as shown in S2-S3. In the composite sample, some of the cobalt atoms are replaced by copper, thus the presence of two transition metals i, e. cobalt and copper possibly generated synergetic effect in the oxide phase, thus superior HER performance is demonstrated. This further emphasizes that the relative amount of $\mathrm{Co}$ and $\mathrm{Cu}$ in the sample can alter the HER activity which needs to optimize for the development of future generation of HER catalysts. Moreover, the copper concertation in the composite has tendency to lower the adsorption energies of atomic hydrogen [72] and consequently faster HER is demonstrated.

The stability of the composite based HER catalyst was evaluated for three hours via chronopotentiometry as shown in Figure 6a. The response of catalyst is highly stable, and it showed a negligible potential drop with time. Thus, we assume that this catalyst can be used for widespread applications. In addition, the durability of the $\mathrm{Co}_{3} \mathrm{O}_{4}-\mathrm{CuO}$ catalyst was investigated through cyclic voltammetry at a scan rate of $10 \mathrm{mV} / \mathrm{s}$ and after 2000 cycles of CV, the LSV response in terms of potential shift was found to be negligible as shown in Figure $6 \mathrm{~b}$. The considerable stability and durability of composite catalyst gives alternative possibility to replace the precious Pt-based catalysts for hydrogen production.

To make a deeper insight on the HER kinetics, the electrochemical impedance spectroscopy (EIS) was performed in a frequency range of $100 \mathrm{kHz}$ to $0.1 \mathrm{~Hz}$ in $1 \mathrm{M} \mathrm{KOH}$ solution at the onset potential of $-0.3 \mathrm{~V}$ RHE and an amplitude of $10 \mathrm{mV}$. The Nyquist plots and the equivalent circuit (as an inset) are shown in Figure 7a. Also, the bode plots are developed using same EIS data as

shown in Figure $7 \mathrm{~b}$ and $7 \mathrm{c}$. The fitted resistance values are summarized in Table 1. This equivalent electric circuit contains the solution resistance $\left(R_{s}\right)$, Faradaic charge-transfer resistance of HER $\left(\mathrm{R}_{\mathrm{ct}}\right)$, and the double-layer capacitance $\left(\mathrm{C}_{\mathrm{dl}}\right)$. As shown in Figure 7 , the $\mathrm{R}_{\mathrm{ct}}(173.2 \Omega)$ for CuO$\mathrm{Co}_{3} \mathrm{O}_{4}$ is apparently smaller and the higher $\mathrm{C}_{\mathrm{dl}}(1.97 \mathrm{mF})$ compared to the pristine $\mathrm{CuO}$ and $\mathrm{Co}_{3} \mathrm{O}_{4}$ suggesting a decrease in the HER resistance and consequently favorable HER catalytic activity in 
alkaline solution is demonstrated [73-75]. The performance of the developed electrocatalyst is superior the recently reported HER catalysts in terms of Tafel slope and at low potential of -0.288 $\mathrm{V}$ for the current density of $10 \mathrm{~mA} / \mathrm{cm}^{2}$ as given in Table $\mathrm{S} 1$.

\section{Conclusions}

This study indicates that the incorporation of copper into the precursors of $\mathrm{Co}_{3} \mathrm{O}_{4}$ nanowires can activate the cobalt oxide material into a highly efficient electro-catalyst toward HER. The composite $\mathrm{Co}_{3} \mathrm{O}_{4}-\mathrm{CuO}$ has performance comparable to the best HER catalysts reported in alkaline media. The addition of copper did not change the morphology of $\mathrm{Co}_{3} \mathrm{O}_{4}$, but it tuned the electronic, catalytic sites and consequently excellent HER performance is achieved. The performance of the proposed catalyst in terms of Tafel slope, approximately $65 \mathrm{mVdec}^{-1}$, and to produce $10 \mathrm{~mA} / \mathrm{cm}^{2}$ current density at a low potential of $0.288 \mathrm{~V}$ vs RHE are showing an advancement in the catalyst design based on $\mathrm{Co}_{3} \mathrm{O}_{4}$ materials for $\mathrm{HER}$. The $\mathrm{Co}_{3} \mathrm{O}_{4}-\mathrm{CuO}$ material has shown a good stability and durability in an alkaline solution. The EIS results have shown that the HER is highly favorable on the $\mathrm{Co}_{3} \mathrm{O}_{4}-\mathrm{CuO}$ surface due to the smaller charge transfer resistance and higher capacitance values. These results provide new horizons for the development of a future generation of high-performance cobalt based electro-catalysts. Also this functional material can be capitalized into diverse energy storage systems. 


\section{References}

[1] Crabtree GW, Dressel Haus MS, Buchanan MV. The Hydrogen Economy. Phys. Today. $2004,57,39$.

[2] Dressel Haus MS, Thomas IL. Alternative energy technologies. Nature. 2001, 414, 332-337.

[3] Nocera DG. The artificial leaf. Acc. Chem. Res. 2012, 45, 767-776.

[4] Walter MG, Warren EL, McKone JR, Boettcher SW, Mi Q, Santori EA, Lewis NS. Solar water splitting cells. Chem. Rev. 2010, 110, 6446-73.

[5] Carmo M, Fritz DL, Merge J, Stolten D. A comprehensive review on PEM water electrolysis. Int. J. Hydrogen Energy, 2013, 38, 4901-4934.

[6] Holladay JD, Hu J, King DL, Wang Y. An overview of hydrogen production technologies. Catal. Today, 2009, 139, 244-260.

[7] Zeng K, Zhang D. Recent progress in alkaline water electrolysis for hydrogen production and applications. Prog. Energ. Combust. 2010, 36, 307-326.

[8] Suntivich J, May KJ, Gasteiger HA, Goodenough JB, Shao-Horn YA. A perovskite oxide optimized for oxygen evolution catalysis from molecular orbital principles. Science. 2011, 334, 1383-5.

[9] Choi CL, Feng J, Li Y, Wu J, Zak A, Tenne R, Dai H. WS 2 nanoflakes from nanotubes for electrocatalysis. Nano Res.2013, 6, 921-928.

[10] Tueysuez, H.; Hwang, Y.J.; Khan, S.B.; Asiri, A.M.; Yang, P. Mesoporous Co3O4 as an electrocatalyst for water oxidation. Nano Res. 2013, 6, 47-54.

[11] Gong M, Zhou W, Tsai M-C, Zhou J, Guan M, Lin M-C, Zhang B, Hu Y, Wang D-Y, Yang J, Pennycook S J, Hwang B-J, Dai H. Nanoscale nickel oxide/nickel heterostructures for active hydrogen evolution electrocatalysis. Nat. Commun. 2014, 5, 4695.

[12] Wang PT, Jiang KZ, Wang GM, Yao JL, Huang XQ. Phase and interface engineering of platinum-nickel nanowires for efficient electrochemical hydrogen evolution. Angew. Chem. Int. Ed. 2016, 55, 12859-12863.

[13] Lukowski MA, Daniel AS, Meng F, Forticaux A, Li L, Jin S. Enhanced hydrogen evolution catalysis from chemically exfoliated metallic MoS2 nanosheets. J. Am. Chem. Soc. 2013, 135, 10274-7.

[14] Faber MS, Dziedzic R, Lukowski MA, Kaiser NS, Ding Q, Jin S. High-Performance Electrocatalysis Using Metallic Cobalt Pyrite (CoS2) Micro- and Nanostructures. J. Am. Chem. Soc. 2014,136, 10053-10061. 
[15] Voiry D, Yamaguchi H, Li J, Silva R, Alves DCB, Fujita T, Chen M, Asefa T, Shenoy V B, Eda G, Chhowalla. M. Enhanced catalytic activity in strained chemically exfoliated $\mathrm{WS}_{2}$ nanosheets for hydrogen evolution. Nat. Mater. 2013, 12, 850-5.

[16] Cummins DR, Martinez U, Sherehiy A, Kappera R, Martinez-Garcia A, Schulze RK, Jasinski J, Zhang J, Gupta RK, Lou J, Chhowalla M, Sumanasekera G, Mohite AD, Sunkara MK, Gupta G. Efficient hydrogen evolution in transition metal dichalcogenides via a simple one-step hydrazine reaction. Nat. Commun. 2016, 7, 11857.

[17] Wang D-Y, Gong M, Chou H-L, Pan C-J, Chen H-A, Wu Y, Lin M-C, Guan M, Yang J, Chen C-W, Wang Y-L, Hwang B-J, Chen C-C, Dai HJ. Highly active and stable hybrid catalyst of cobalt-doped FeS2 nanosheets-carbon nanotubes for hydrogen evolution reaction. Am. Chem. Soc. 2015, 137, 1587-92.

[18] Hinnemann B, Moses PG, Bonde J, Jørgensen KP, Nielsen JH, Horch S, Chorkendorff I, Nørskov JK. Biomimetic hydrogen evolution: MoS2 nanoparticles as catalyst for hydrogen evolution. J. Am. Chem. Soc. 2005, 127, 5308-9.

[19] Kong D, Wang H, Lu Z, Cui Y. CoSe2 nanoparticles grown on carbon fiber paper: an efficient and stable electrocatalyst for hydrogen evolution reaction. J. Am. Chem. Soc. 2014, 136, 4897-900.

[20] Deng S, Zhong Y, Zeng Y, Wang Y, Yao Z, Yang F, Lin S, Wang X, Lu X, Xia X, Tu J. Directional Construction of Vertical Nitrogen-Doped 1T-2H $\mathrm{MoSe}_{2} / \mathrm{Graphene}$ Shell/Core Nanoflake Arrays for Efficient Hydrogen Evolution Reaction. Adv. Mater. 2017, 29, 1700748.

[21] Shi YM, Zhang B. Recent advances in transition metal phosphide nanomaterials: Synthesis and applications in hydrogen evolution reaction. Chem. Soc. Rev. 2016, 45, 1781.

[22] Tian JQ, Liu Q, Asiri AM, Sun XP. Self-Supported Nanoporous Cobalt Phosphide Nanowire Arrays: An Efficient 3D Hydrogen-Evolving Cathode over the Wide Range of pH 0-14. J. Am. Chem. Soc. 2014, 136, 7587-7590.

[23] Zhang G, Wang G, Liu Y, Liu H, Qu J, Li J. Highly Active and Stable Catalysts of Phytic Acid-Derivative Transition Metal Phosphides for Full Water Splitting. J. Am. Chem. Soc. 2016, 138, 14686-14693.

[24] Xie JF, Li S, Zhang X, Zhang J, Wang R, Zhang H, Pan B, Xie Y. Atomically-thin molybdenum nitride nanosheets with exposed active surface sites for efficient hydrogen evolution. Chem. Sci. 2014, 5, 4615-4620.

[25] Gao DQ, Zhang J, Wang T, Xiao W, Tao K, Xue D, Ding J. Metallic Ni3N nanosheets with exposed active surface sites for efficient hydrogen evolution. J. Mater. Chem. A. 2016, 4, 1736317369. 
[26] Wang S, Wang J, Zhu M, Bao X, Xiao B, Su D, Li H, Wang Y. Molybdenum-CarbideModified Nitrogen-Doped Carbon Vesicle Encapsulating Nickel Nanoparticles: A Highly Efficient, Low-Cost Catalyst for Hydrogen Evolution Reaction. J. Am. Chem. Soc. 2015,137, 15753-9.

[27] Liao L, Wang S, Xiao J, Bian X, Zhang Y, Scanlon MD, Hu X, Tang Y, Liu B, Girault HH. A nanoporous molybdenum carbide nanowire as an electrocatalyst for hydrogen evolution reaction. Energy Environ. Sci. 2014, 7, 387-392.

[28] Yan X, Tian L, He M, Chen X. Three-Dimensional Crystalline/Amorphous $\mathrm{Co} / \mathrm{Co}_{3} \mathrm{O}_{4}$ Core/Shell Nanosheets as Efficient Electrocatalysts for the Hydrogen Evolution Reaction. Nano Lett., 2015, 15, 6015-6021.

[29] Zhang J, Wang T, Liu P, Liao Z, Liu S, Zhuang X, Chen M, Zschech E, Feng X. Efficient hydrogen production on MoNi4 electrocatalysts with fast water dissociation kinetics. Nat. Commun. 2017, 8, 15437.

[30] McKone JR, Sadtler BF, Werlang CA, Lewis NS, Gray HB. Ni-Mo Nanopowders for Efficient Electrochemical Hydrogen Evolution. ACS Catal. 2013, 3, 166-169.

[31] Liu T, Wang K, Du G, Asiri AM, Sun X. Self-supported CoP nanosheet arrays: a nonprecious metal catalyst for efficient hydrogen generation from alkaline NaBH4 solution J. Mater. Chem. A 2016, 4, 13053-13057.

[32] Dong Z, Wang J, Ren Z, Dong G. Ortho C-H Acylation of Aryl Iodides by Palladium/Norbornene Catalysis Angew. Chem. Int. Ed. 2014, 53, 12855-12859.

[33] Wang Z, Liu H, Ge R, Ren X, Ren J, Yang D, Zhang L, Sun X. Phosphorus-Doped $\mathrm{Co}_{3} \mathrm{O}_{4}$ Nanowire Array: A Highly Efficient Bifunctional Electrocatalyst for Overall Water Splitting ACS CATAL. 2018, 8, 2236-2241.

[34] Liu T, Liu D, Qu F, Wang D, Zhang L, Ge R, Hao S, Ma Y, Du G, Asiri AM, Chen L, Sun $\mathrm{X}$. Enhanced Electrocatalysis for Energy-Efficient Hydrogen Production over CoP Catalyst with Nonelectroactive Zn as a Promoter. Adv. Energy Mater. 2017, 7, 1700020.

[35] Tang C, Zhang R, Lu W, He L, Jiang X, Asiri AM, Sun X. Fe-Doped CoP Nanoarray: A Monolithic Multifunctional Catalyst for Highly Efficient Hydrogen Generation. Adv. Mater. 2017, $29,1602441$.

[36] Liu T, Wang K, Du G, Asiri AM, Sun X. Self-supported CoP nanosheet arrays: a nonprecious metal catalyst for efficient hydrogen generation from alkaline $\mathrm{NaBH}_{4}$ solution. J. Mater. Chem. A 2016, 4, 13053-13057.

[37] Hall DE. Electrodes for Alkaline Water Electrolysis. J. Electrochem. Soc. 1981, 128, 740746. 
[38] Janjua MBI, Leroy RL. Electrocatalyst Performance in Industrial Water Electrolysers. Int. J. Hydrogen Energy. 1985, 10, 11-19.

[39] Brown DE, Mahmood MN, Turner AK, Hall SM, Fogarty PO. Low overvoltage electrocatalysts for hydrogen evolving electrodes. Int. J. Hydrogen Energy.1982, 7, 405-410.

[40] Brown DE, Mahmood MN, Man MCM, Turner AK. Preparation and characterization of low overvoltage transition metal alloy electrocatalysts for hydrogen evolution in alkaline solutions. Electrochim. Acta. 1984, 29, 1551-1556.

[41] Endoh E, Otouma H, Morimoto T, Oda Y. New Raney nickel composite-coated electrode for hydrogen evolution. Int. J. Hydrogen Energy.1987, 12, 473-479.

[42] Birry L, Lasia A. Studies of the Hydrogen Evolution Reaction on Raney NickelMolybdenum Electrodes. J. Appl. Electrochem. 2004, 34, 735-749.

[43] Damian A, Omanovic S. Ni and NiMo hydrogen evolution electrocatalysts electrodeposited in a polyaniline matrix. J. Power Sources. 2006, 158, 464-476.

[44] Lupi C, Dell'Era A, Pasquali M. Nickel-cobalt electrodeposited alloys for hydrogen evolution in alkaline media. Int. J. Hydrogen Energy. 2009, 34, 2101-2106.

[45] Popczun EJ, McKone JR, Read CG, Biacchi AJ, Wiltrout AM, Lewis NS, Schaak RE. Nanostructured Nickel Phosphide as an Electrocatalyst for the Hydrogen Evolution Reaction. J. Am. Chem. Soc.2013, 135, 9267-9270.

[46] Sheng W, Bivens AP, Myint MNZ, Zhuang Z, Forest RV, Fang Q, Chen JG, Yan Y. Non-precious metal electrocatalysts with high activity for hydrogen oxidation reaction in alkaline electrolytes. Energ. Environ. Sci. 2014, 7, 1719-1724.

[47] Xu X, Su C, Zhou W, Zhu Y, Chen Y, Shao Z. Co-doping Strategy for Developing Perovskite Oxides as Highly Efficient Electrocatalysts for Oxygen Evolution Reaction. Advanced Science, 2016, 3, 1500187.

[48] Xu X, Chen Y, Zhou W, Zhong Y, Guan D, Shao Z. Earth-Abundant Silicon for Facilitating Water Oxidation over Iron-Based Perovskite Electrocatalyst. Adv. Mater. Interfaces 2018, 5, 1701693.

[49] Burke MS, Enman LJ, Batchellor AS, Zou S, Boettcher SW. Oxygen Evolution Reaction Electrocatalysis on Transition Metal Oxides and (Oxy)hydroxides: Activity Trends and Design Principles.Chem.Mater.2015,27,7549-7558.

[50] Grimaud A, May KJ, Carlton CE, Lee Y-L, Risch M, Hong W T, Zhou J, Shao-Horn Y. Double perovskites as a family of highly active catalysts for oxygen evolution in alkaline solution. Nat. Commun. 2013, 4, 2439. 
[51] Desmond Ng JW, García-Melchor M, Bajdich M, Chakthranont P, Kirk C, Vojvodic A, Jaramillo TF. Gold-supported cerium-doped NiOx catalysts for water oxidation. Nat. Energy. 2016, 1, 16053.

[52] Weng Z, Liu W, Yin LC, Fang R, Li M, Altman EI.;Fan, Q.; Li, F.; Cheng, H.M.; Wang, H. Metal/Oxide Interface Nanostructures Generated by Surface Segregation for Electrocatalysis. Nano Lett. 2015, 15, 7704-7710.

[53] Xu X, Zhong Y, Shao Z. Double Perovskites in Catalysis, Electrocatalysis, and Photo(electro)catalysis. Trends in Chemistry 2019, 1, 410-424

[54] Xu X, Chen Y, Zhou W, Zhu Z, Su C, Liu M, Shao Z. A Perovskite Electrocatalyst for Efficient Hydrogen evolution reaction. Adv. Mater. 2016, 28, 6442-6448

[55] Yin H, Zhao S, Zhao K, Muqsit A, Tang H, Chang L, Zhao H, Gao Y, Tang Z, Ultrathin platinum nanowires grown on single-layered nickel hydroxide with high hydrogen evolution activity. Nat.Commun.2015, 6, 6430.

[56] Subbaraman R, Tripkovic D, Chang K-C, Strmcnik D, Paulikas AP, Hirunsit P, Chan M, Greeley J, Stamenkovic V, Markovic N M. Trends in activity for the water electrolyser reactions on 3d M(Ni,Co,Fe,Mn) hydr(oxy)oxide catalysts. Nat. Mater. 2012, 11, 550-7.

[57] Gong M, Wang DY, Chen CC, Hwang BJ, Dai H. A mini review on nickel-based electrocatalysts for alkaline hydrogen evolution reaction. Nano Res. 2016, 9, 28-46.

[58] Xu L, Jiang Q, Xiao Z, Li X, Huo J, Wang S, Dai L. Plasma-Engraved $\mathrm{Co}_{3} \mathrm{O}_{4}$ Nanosheets with Oxygen Vacancies and High Surface Area for the Oxygen Evolution Reaction. Angew Chem Int Ed Engl. 2016, 55, 5277-81.

[59] Liang Y, Li Y, Wang H, Zhou J, Wang J, Regier T, Dai H. $\mathrm{Co}_{3} \mathrm{O}_{4}$ nanocrystals on graphene as a synergistic catalyst for oxygen reduction reaction. Nat. Mater. 2011, 10, 780-6.

[60] Gao R, Li Z, Zhang X, Zhang J, Hu Z, Liu X. Carbon-Dotted Defective CoO with Oxygen Vacancies: A Synergetic Design of Bifunctional Cathode Catalyst for Li-O2 Batteries. ACS Catal. 2016, 6, 400-406.

[61] Wang H, Qing C, Guo J, Aref AA, Sun D, Wang B, Tang Y. Highly conductive carbon-CoO hybrid nanostructure arrays with enhanced electrochemical performance for asymmetric supercapacitors. J. Mater. Chem. A. 2014, 2, 11776-11783.

[62] Liu X, Jia H, Sun Z, Chen H, Xu P, Du P. Nanostructured copper oxide electrodeposited from copper (II) complexes as an active catalyst for electrocatalytic oxygen evolution reaction. Electrochem. Commun. 2014, 46, 1-4. 
[63] Liu SCX, Sun Z, Ren Y, Zhang X, Du P. Self-Supported Copper Oxide Electrocatalyst for Water Oxidation at Low Overpotential and Confirmation of Its Robustness by $\mathrm{Cu}$ K-Edge X-ray Absorption Spectroscopy. J. Phys. Chem. C. 2015, 120, 831.

[64] Yu J, Hai Y, Jaroniec M. Photocatalytic hydrogen production over CuO-modified titania. J. Colloid Interface Sci. 2011, 357, 223-228.

[65] Liu X, Zheng H, Sun Z, Han A, Du P. Earth-Abundant Copper-Based Bifunctional Electrocatalyst for Both Catalytic Hydrogen Production and Water Oxidation. ACS Catal. 2015, 5,1530-1538.

[66] Mcintyre NS, Cook MG. X-ray photoelectron studies on some oxides and hydroxides of cobalt, nickel, and copper. Anal. Chem. 1975, 47, 2208-2213.

[67] Ling T, Yan D-Y, Wang H, Jiao Y, Hu Z, Zheng Y, Zheng L, Mao J, Liu H, Du X-W, Jaroniec M, Qiao S-Z. Activating cobalt (II) oxide nanorods for efficient electrocatalysis by strain engineering. Nat. Commun. 2017, 8, 1509.

[68] Zheng Y, Jiao Y, Jaroniec M, Qiao SZ. Advancing the electrochemistry of the hydrogenevolution reaction through combining experiment and theory. Angew. Chem. Int. Ed. 2015, 54, $52-65$.

[69] Carrasco J, López-Durán D, Liu Z, Duchoň T, Evans J, Senanayake SD, Crumlin EJ, Matolín V, Rodríguez JA, Ganduglia-Pirovano MV. In Situ and Theoretical Studies for the Dissociation of Water on an Active $\mathrm{Ni} / \mathrm{CeO}_{2}$ Catalyst: Importance of Strong Metal-Support Interactions for the Cleavage of O-H Bonds. Angew. Chem. Int. Ed. 2015, 54, 3917-3921.

[70] Vrubel, H.; Moehl, T.; Gratzel, M.; Hu, X.L. Revealing and accelerating slow electron transport in amorphous molybdenum sulphide particles for hydrogen evolution reaction. Chem. Commun. 2013, 49, 8985-8987.

[71] Hod I, Deria P, Bury W, Mondloch JE, Kung C-W, So M, Sampson MD, Peters AW, Kubiak $\mathrm{CP}$, Farha OK, Hupp JT, A porous proton-relaying metal-organic framework material that accelerates electrochemical hydrogen evolution. Nat. Commun. 2015, 6, 8304.

[72] Bandarenka AS, Varela AS, Karamad M, Calle-Vallejo F, Bech L, Perez-Alonso FJ, Rossmeisl J, Stephens IE, Chorkendorff I. Design of an active site towards optimal electrocatalysis: overlayers, surface alloys and near-surface alloys of $\mathrm{Cu} / \mathrm{Pt}(111)$. Angew. Chem. Int. Ed. 2012, 51, 11845-8.

[73] Li Y, Zhang L, Xiang X, Yan D, Li F. Engineering of ZnCo-layered double hydroxide nanowalls toward high-efficiency electrochemical water oxidation. J. Mater. Chem. A, 2014, 2, 13250-13258. 
[74] Lin X, Li X, Li F, Fang Y, Tian M, An X, Fu Y, Jin J, Ma J. Co-Fe nanoparticles coupled nitrogen-enriched porous carbon (CoyFe10-yOx/NPC) nanosheets were successfully synthesized and used as highly effective electrocatalysts for the oxygen evolution reaction (OER) J. Mater. Chem. A, 2016, 4, 6505-6512.

[75] Fang Y, Li X, Zhao S, Wu J, Li F, Tian M, Long X, Jin J, Ma J. Coaxial ultrathin Co1-yFeyOx nanosheet coating on carbon nanotubes for water oxidation with excellent activity. RSC Adv. 2016, 6, 80613-80620. 


\section{Figure Captions}

Figure 1: Scanning electron microscopy images at different magnifications a-b. pure $\mathrm{CuO}, \mathrm{c}-\mathrm{d}$. pure $\mathrm{Co}_{3} \mathrm{O}_{4}$, e-f. $\mathrm{Co}_{3} \mathrm{O}_{4}-\mathrm{CuO}$ composite.

Figure 2: EDS elemental mapping a $\mathrm{Co}_{3} \mathrm{O}_{4}-\mathrm{CuO}$ composite oxide, b EDS spectrum. $\mathrm{Co}_{3} \mathrm{O}_{4}-\mathrm{CuO}$ composite.

Figure 3: XRD spectra for various nanostructured materials a. pure $\mathrm{CuO}$, b. pure $\mathrm{Co}_{3} \mathrm{O}_{4}, \mathrm{c} . \mathrm{Co}_{3} \mathrm{O}_{4}$ $\mathrm{CuO}$ composite.

Figure 4: XPS spectrum (a) Wide scan survey spectrum of $\mathrm{Co}_{3} \mathrm{O}_{4}-\mathrm{CuO}$, (b) $\mathrm{Co} 2 \mathrm{p}$ of $\mathrm{Co}_{3} \mathrm{O}_{4}-\mathrm{CuO}$, (c) $\mathrm{O} 1 \mathrm{~s}$ of $\mathrm{Co}_{3} \mathrm{O}_{4}-\mathrm{CuO}$ (d) $\mathrm{Cu} 2 \mathrm{p}$ of $\mathrm{Co}_{3} \mathrm{O}_{4}-\mathrm{CuO}$

Figure 5: 5a. LSV polarization curves for different catalysts $\mathrm{GCE}$, pure $\mathrm{CuO}$, pure $\mathrm{Co}_{3} \mathrm{O}_{4}$, and $\mathrm{Co}_{3} \mathrm{O}_{4}-\mathrm{CuO}$ composite, $20 \% \mathrm{Pt} / \mathrm{C}$ at scan rate of $5 \mathrm{mV} / \mathrm{s}$ in $1 \mathrm{M} \mathrm{KOH}$ solution at room temperature, 5b. the corresponding Tafel slopes from HER polarization curves for different electrocatalysts

Figure 6: 6a. The chronopotentiometry response at $10 \mathrm{~mA} / \mathrm{cm}^{2}$ of $\mathrm{Co}_{3} \mathrm{O}_{4}-\mathrm{CuO}$ composite for 3 hours, 6b. durability response after 2000 cycles of cyclic voltammetry in $1 \mathrm{M} \mathrm{KOH}$ at a scan rate of $100 \mathrm{mV} / \mathrm{s}$ in the potential window of 0.864 to $1.164 \mathrm{~V}$ vs RHE.

Figure 7: a, Nyquist plots for the HER under an applied potential of $-0.3 \mathrm{~V}$ vs RHE, a frequency range of $100 \mathrm{kHz}$ to $0.1 \mathrm{~Hz}$ and amplitude of $10 \mathrm{mV}$ in $1 \mathrm{M} \mathrm{KOH}$ and Bode (b,c) plots The inset in Figure $7 \mathrm{a}$ is the equivalent circuit used to fit the data. $\mathrm{R}_{\mathrm{s}}$ is the ohmic resistance of the solution, $\mathrm{R}_{\mathrm{ct}}$ is the charge transfer resistance and $\mathrm{C}_{\mathrm{dl}}$ the double layer capacitance.

Figure 1: 

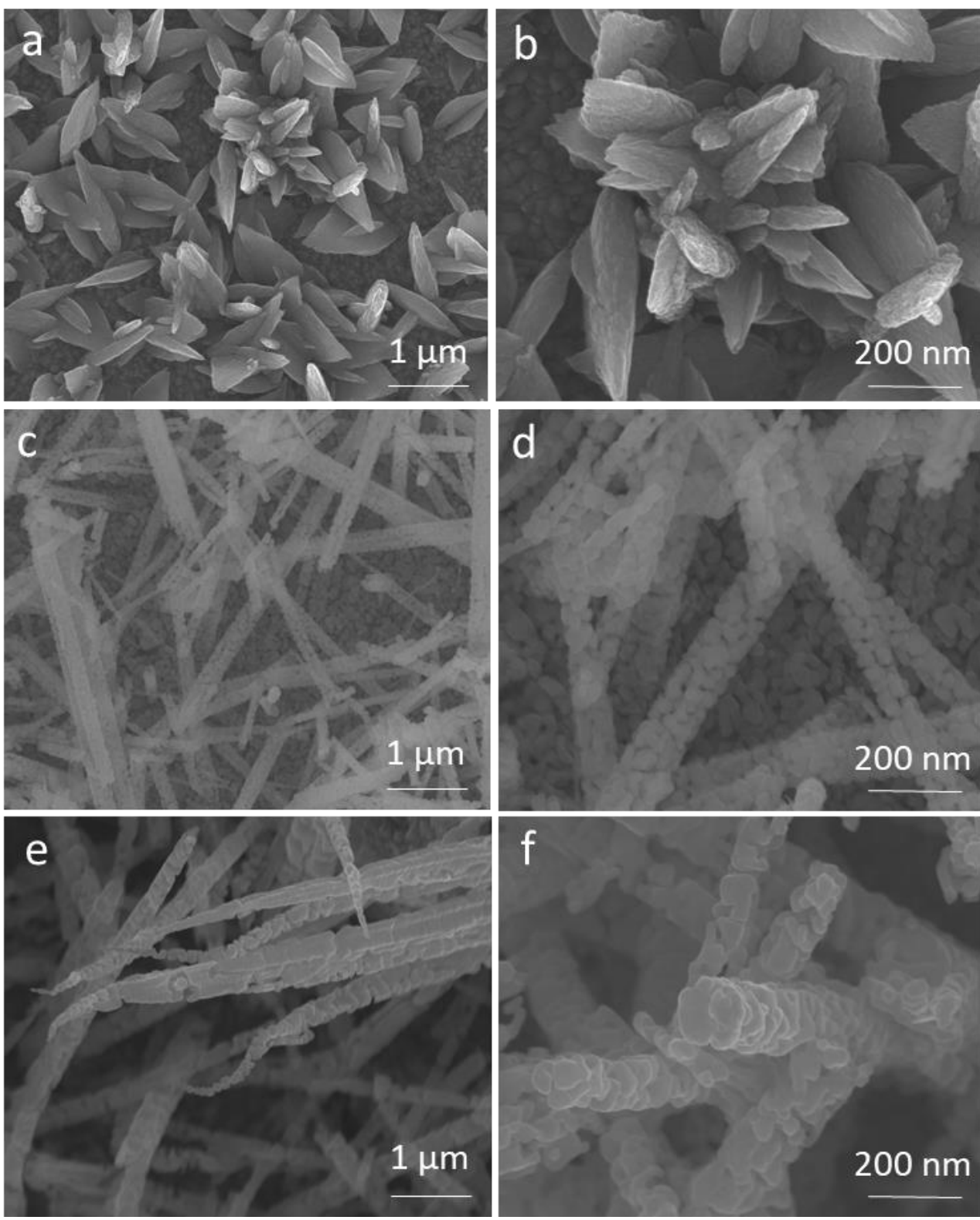
Figure 2:
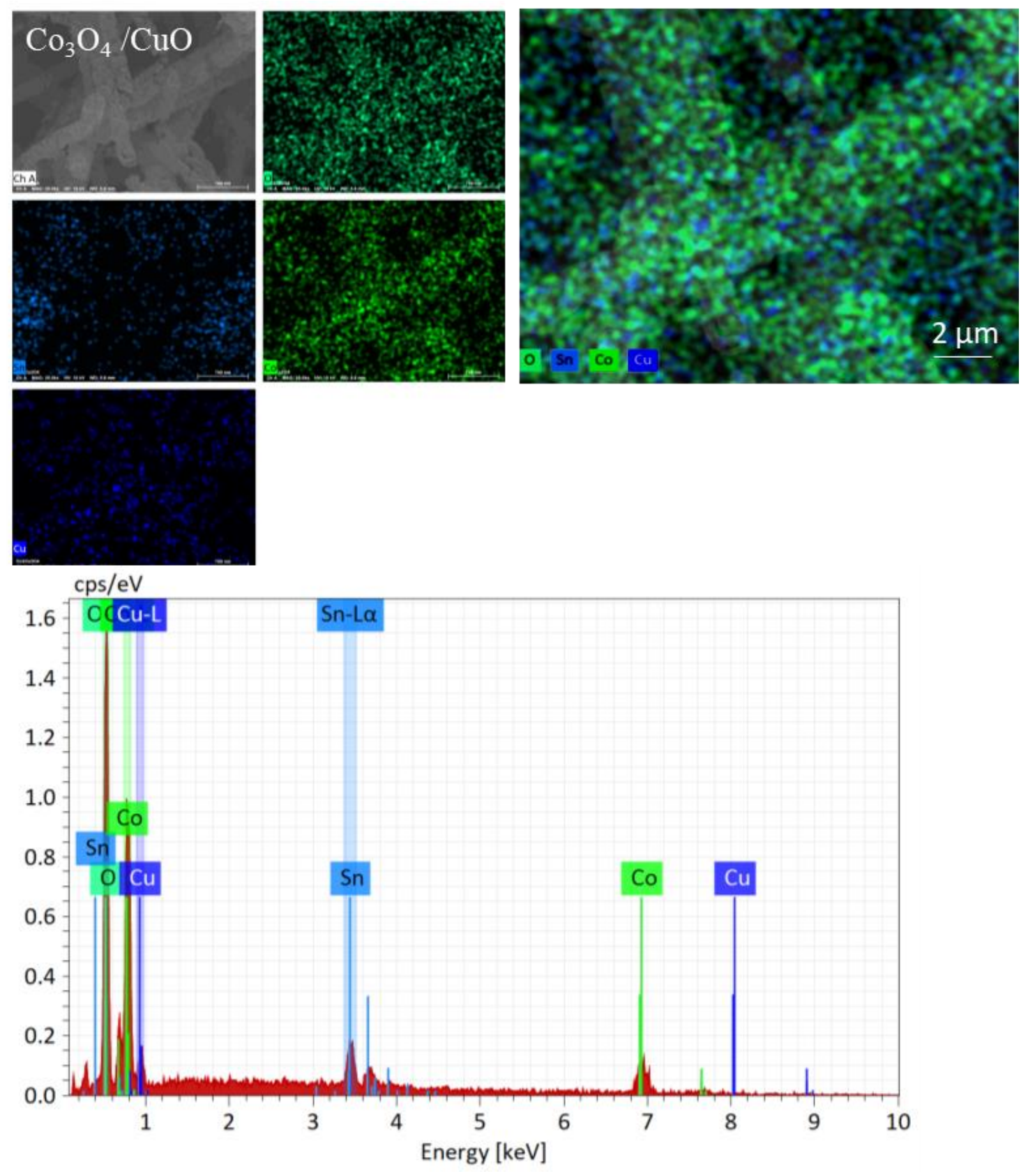
Figure 3:

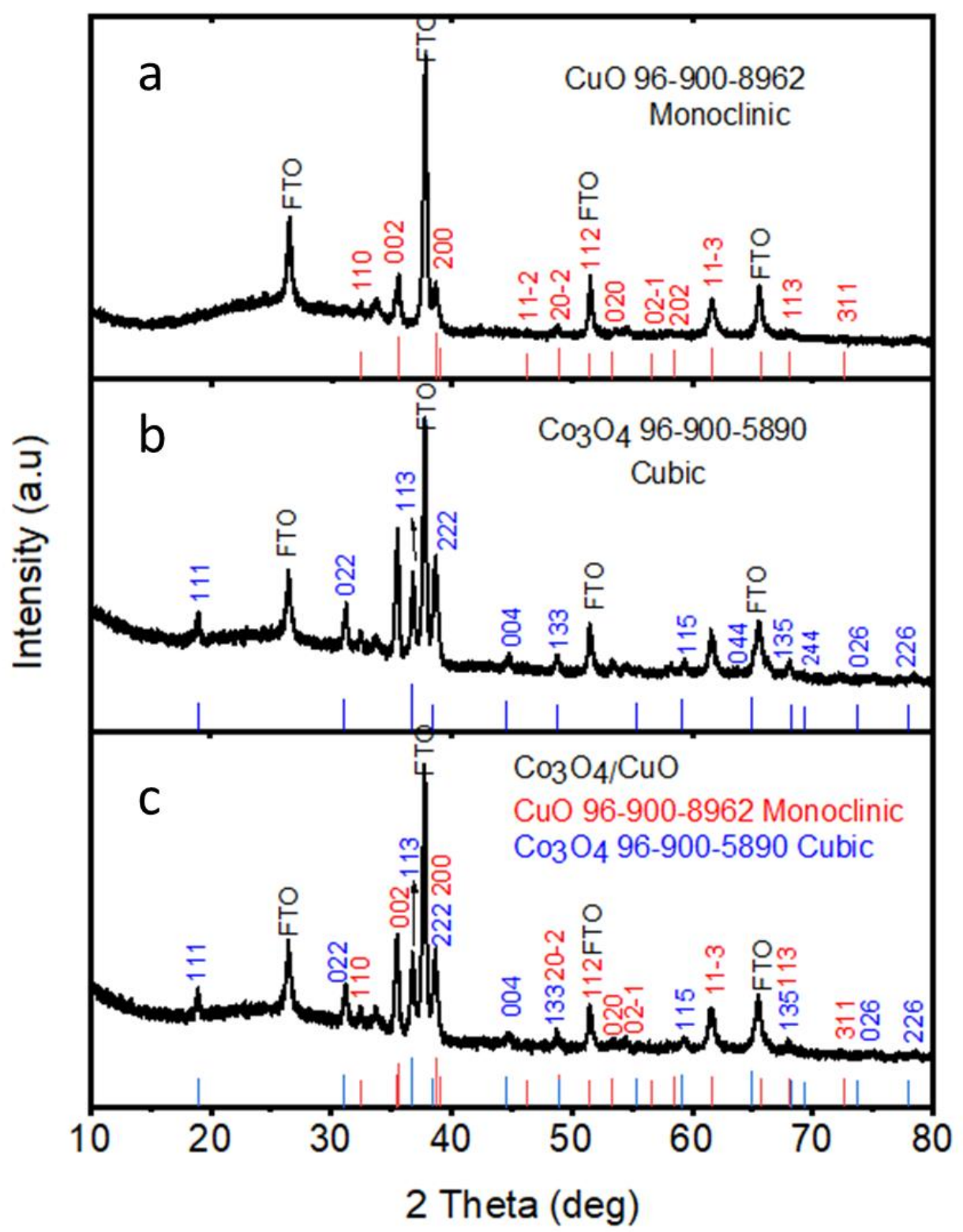

Figure 4. 

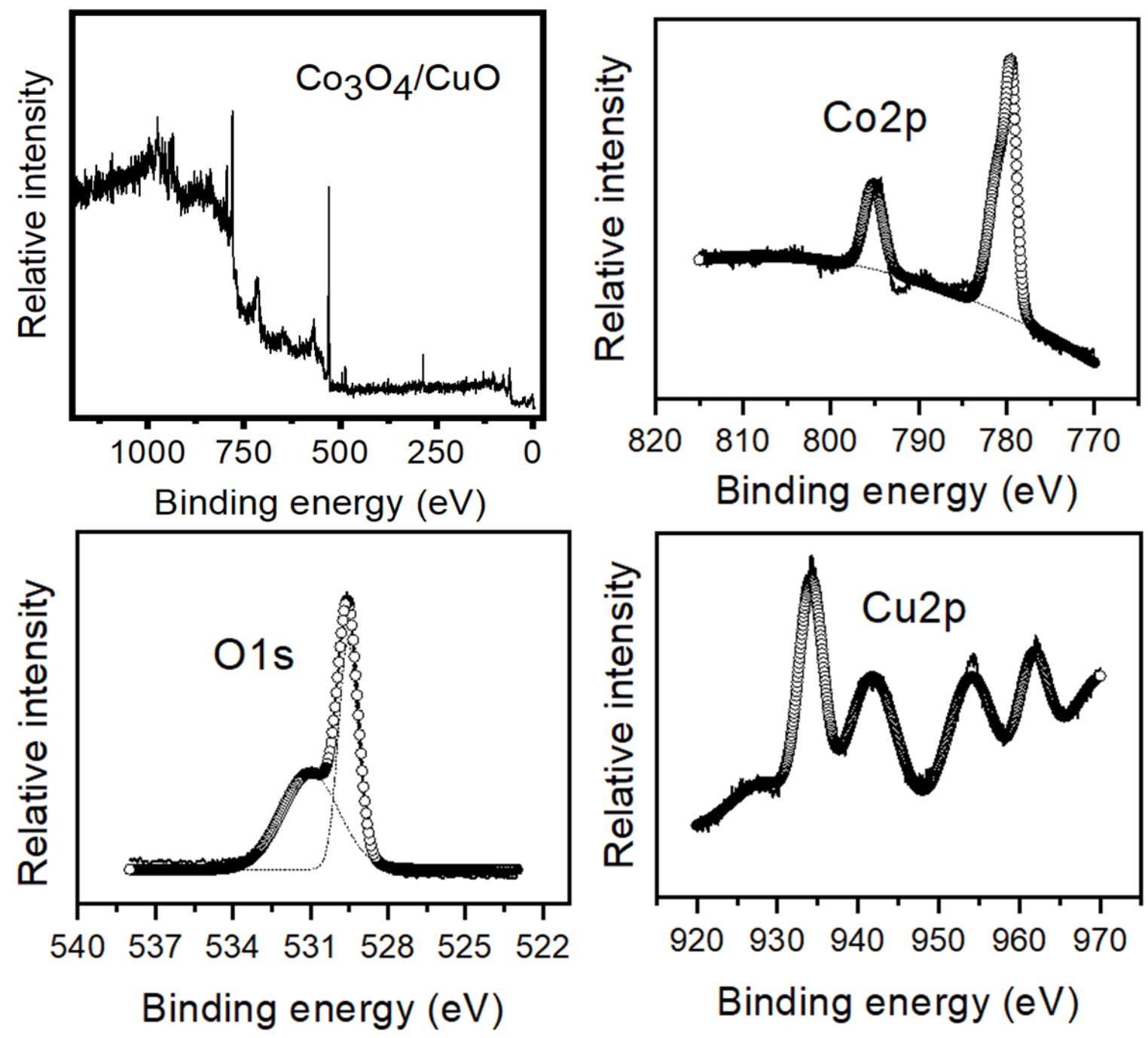
Figure $5(a, b)$ :

a

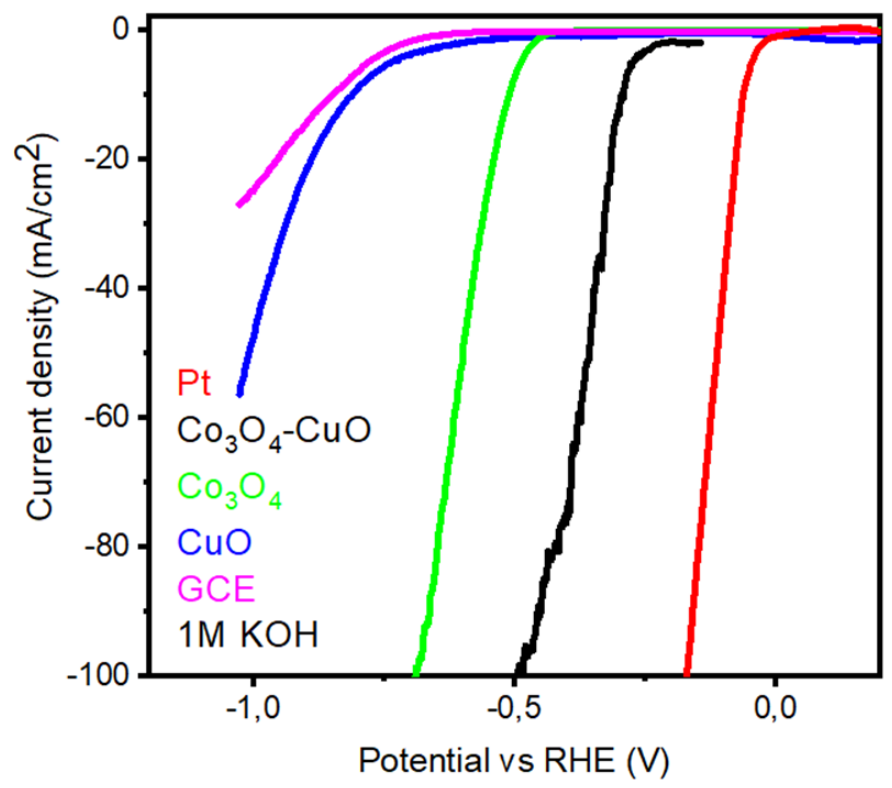

b

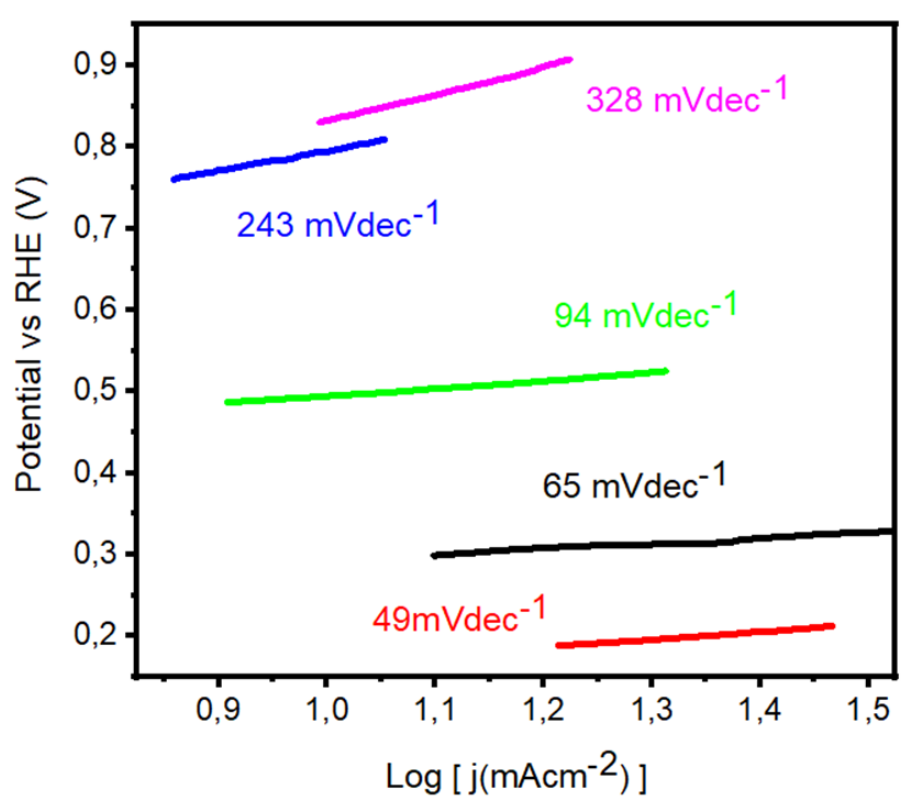


Figure $6(a, b)$ :

a

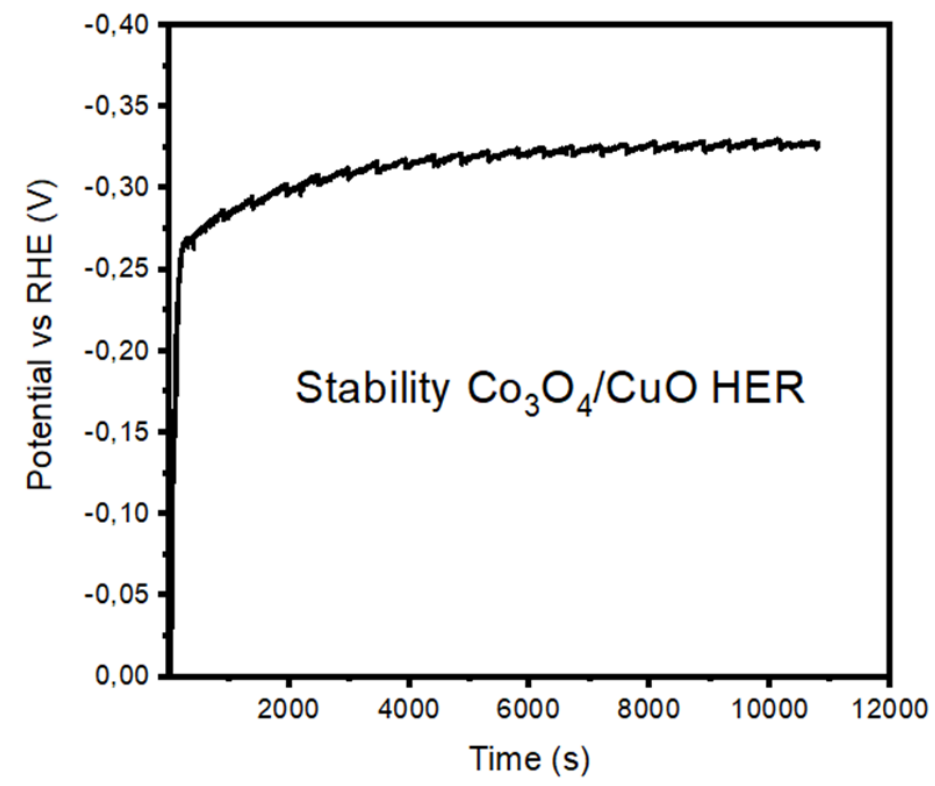

b

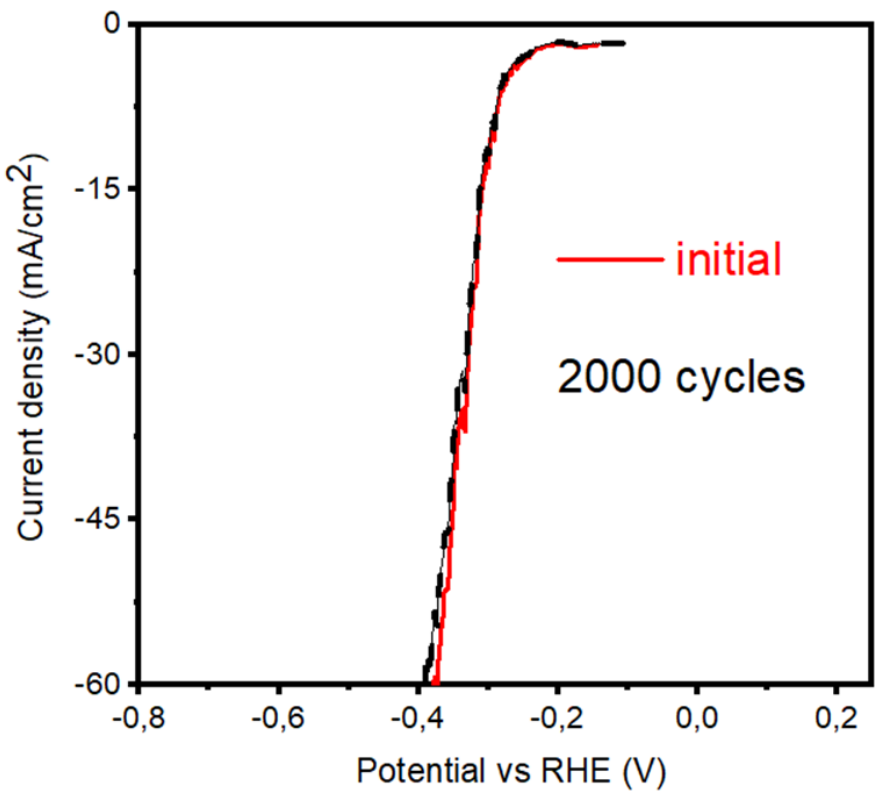


Figure 7

a
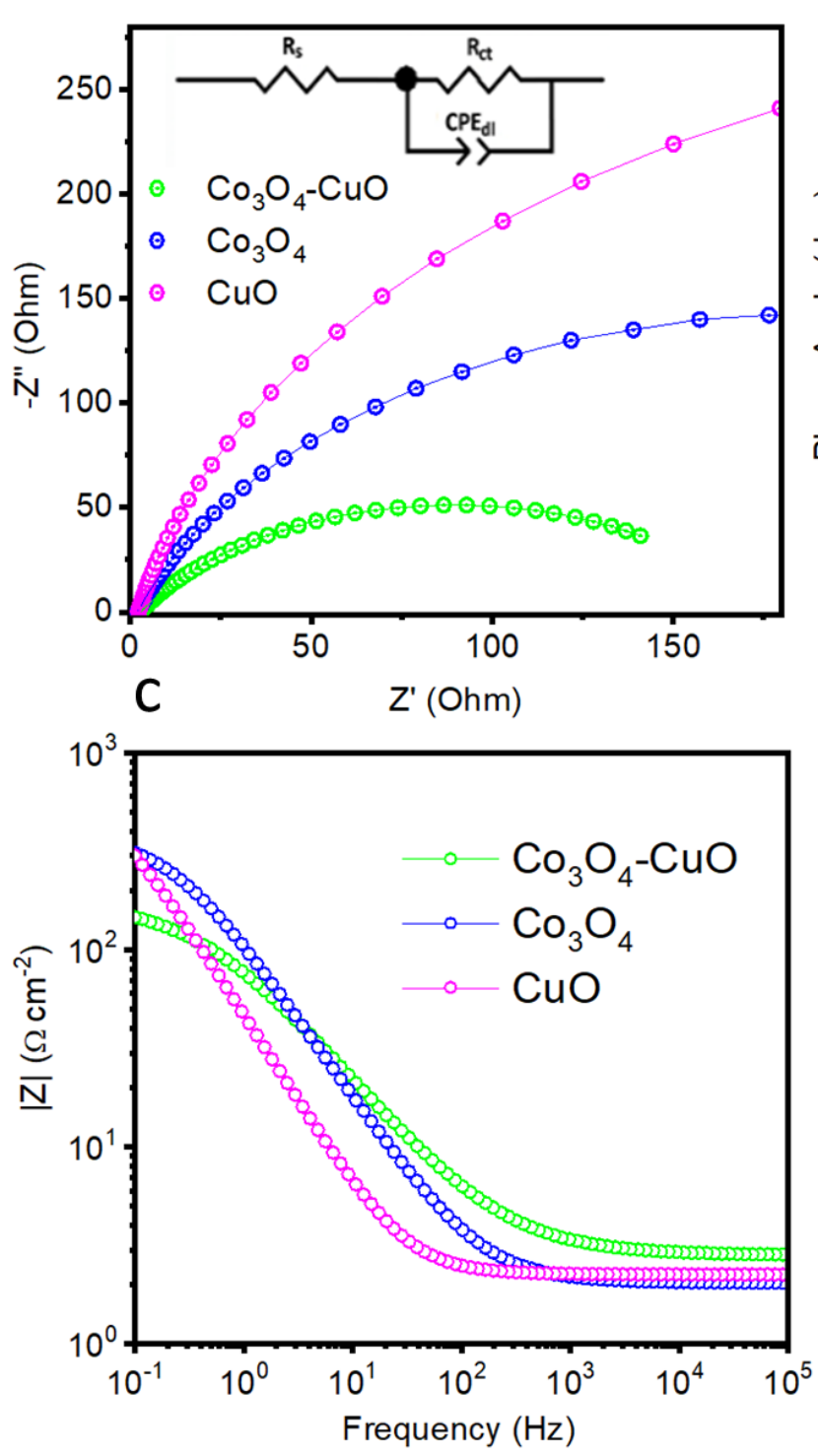

b

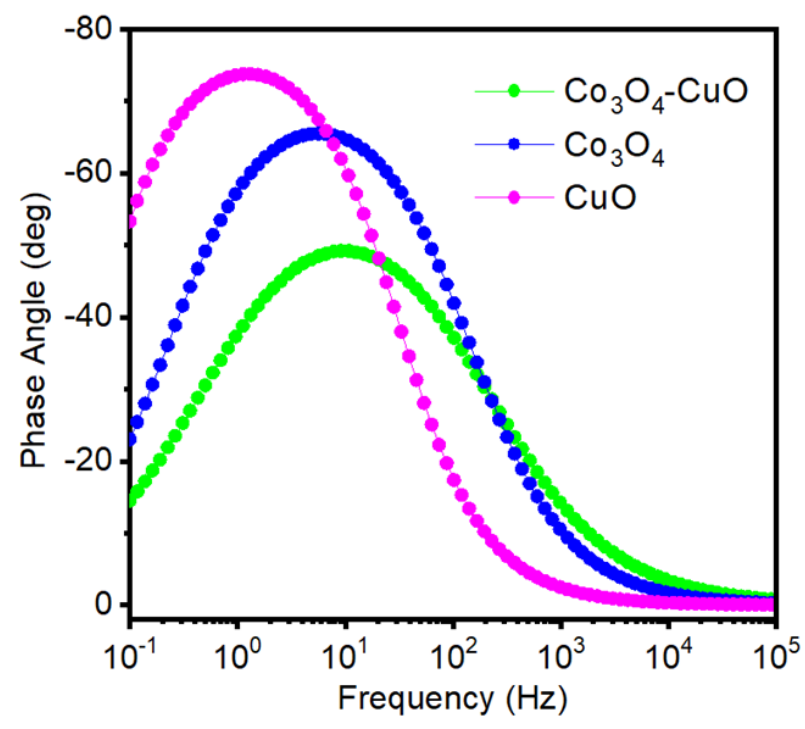


Table 1. The fitted values for the elements of equivalent circuit

\begin{tabular}{|l|l|l|l|}
\hline \multicolumn{1}{|c|}{ Sample } & Rs (Ohm) & Rct(Ohm) & CPE (mF) \\
\hline $\mathrm{CO}_{3} \mathrm{O}_{4}-\mathrm{CuO}$ & 2.82 & 173.20 & 1.97 \\
\hline $\mathrm{Co}_{3} \mathrm{O}_{4}$ & 2.04 & 384.50 & 0.85 \\
\hline $\mathrm{CuO}$ & 2.25 & 656.90 & 0.35 \\
\hline
\end{tabular}




\section{Advanced $\mathrm{Co}_{3} \mathrm{O}_{4}-\mathrm{CuO}$ nano-composite based electrocatalyst for efficient hydrogen evolution reaction in alkaline media}

Aneela Tahira ${ }^{\mathrm{a}}$, Zafar Hussain Ibupoto ${ }^{\mathrm{b}}$, Magnus Willander ${ }^{\mathrm{a}}$, Omer Nur ${ }^{\mathrm{a}}$

${ }^{a}$ Department of Science and Technology, Campus Norrkoping, Linkoping University, SE-60174 Norrkoping, Sweden

${ }^{b}$ Dr. M.A Kazi Institute of Chemistry University of Sindh Jamshoro, 76080, Sindh Pakistan

Corresponding author: Zafar Hussain Ibupoto

Email address: zaffar.ibhupoto@usindh.edu.pk

\section{Supplementary data}

S1: SEM of composite catalyst after stability and durability experiment

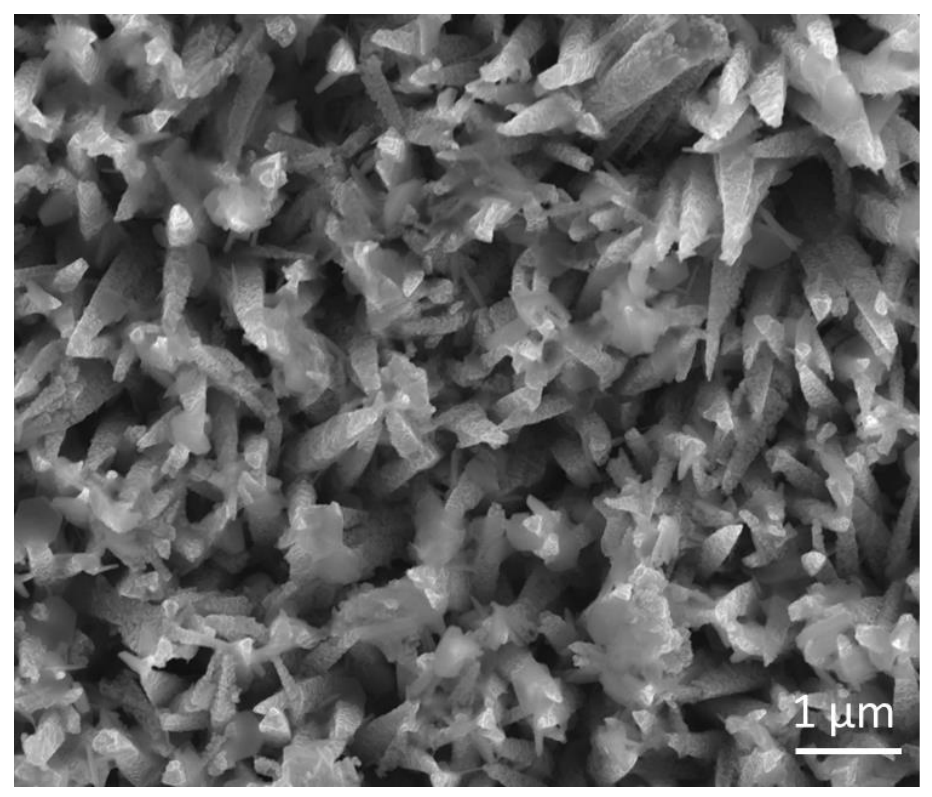


S2: EDS mapping for the elemental distribution in pristine $\mathrm{CuO}$
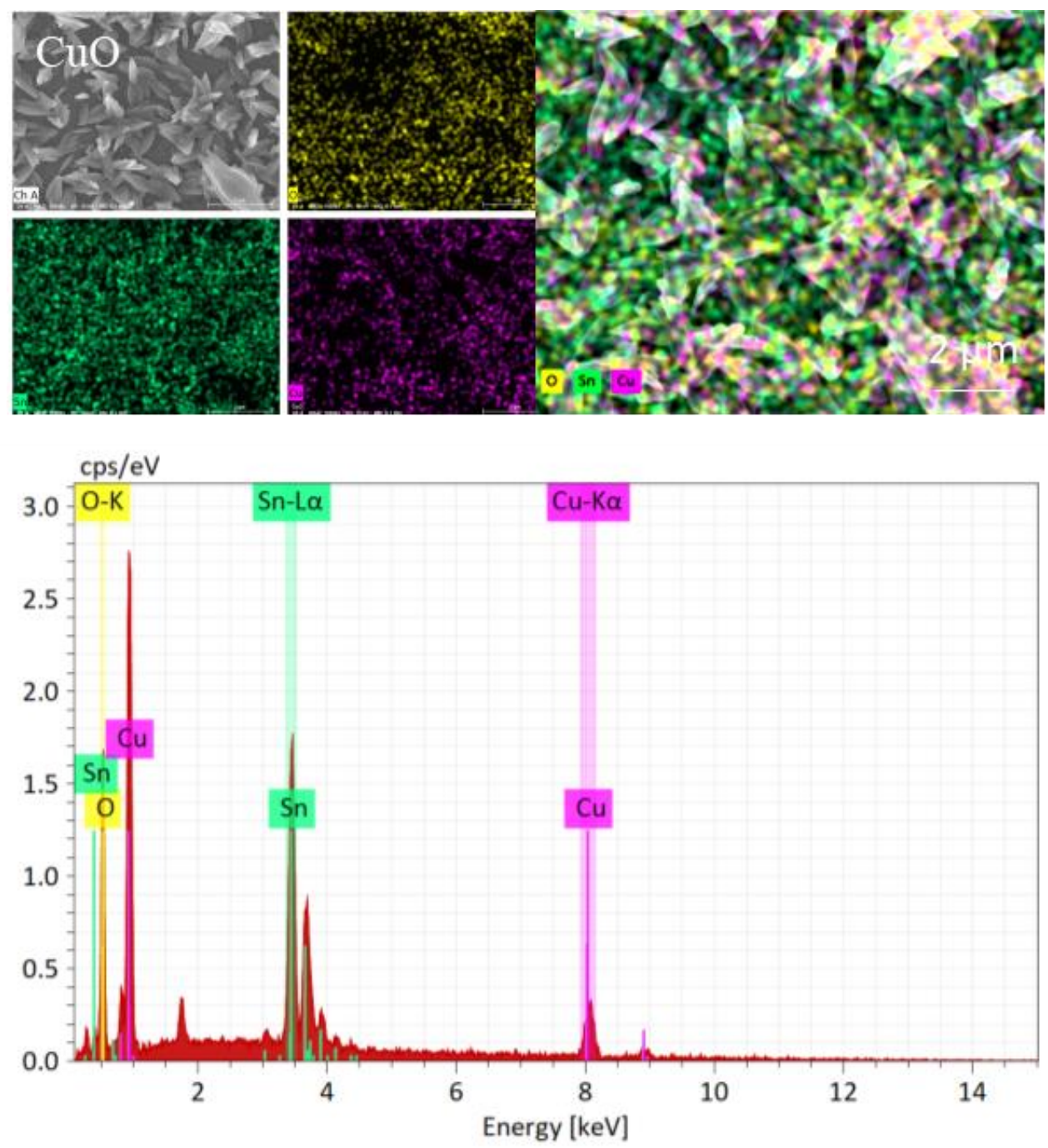
S3: EDS mapping for the elemental distribution in pristine $\mathrm{Co}_{3} \mathrm{O}_{4}$
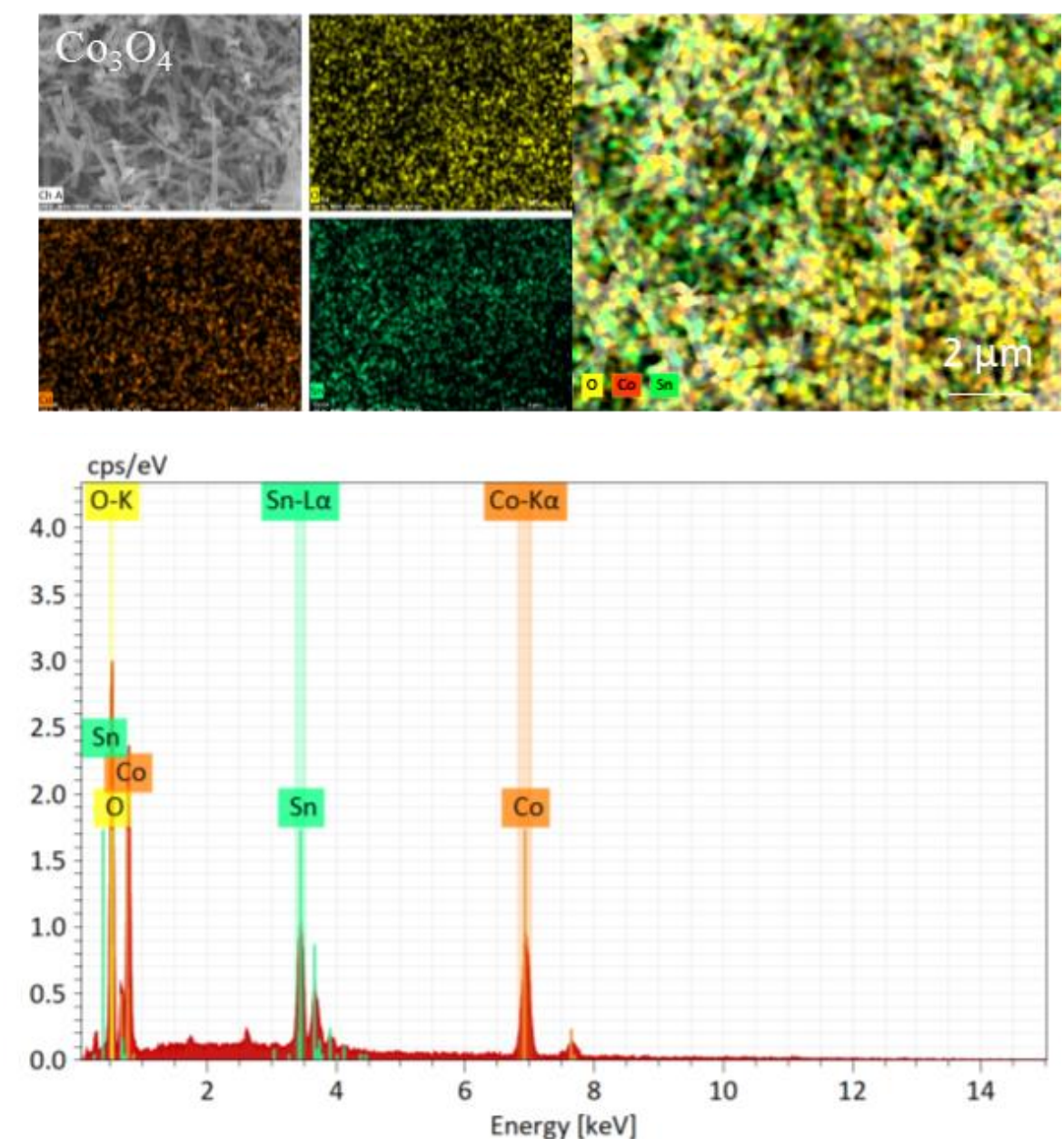
S4. a. Co 2p XPS spectra of pristine $\mathrm{Co}_{3} \mathrm{O}_{4}$, Fitted O 1s for pristine $\mathrm{Co}_{3} \mathrm{O}_{4}$ b. XPS spectra of $\mathrm{CuO}$
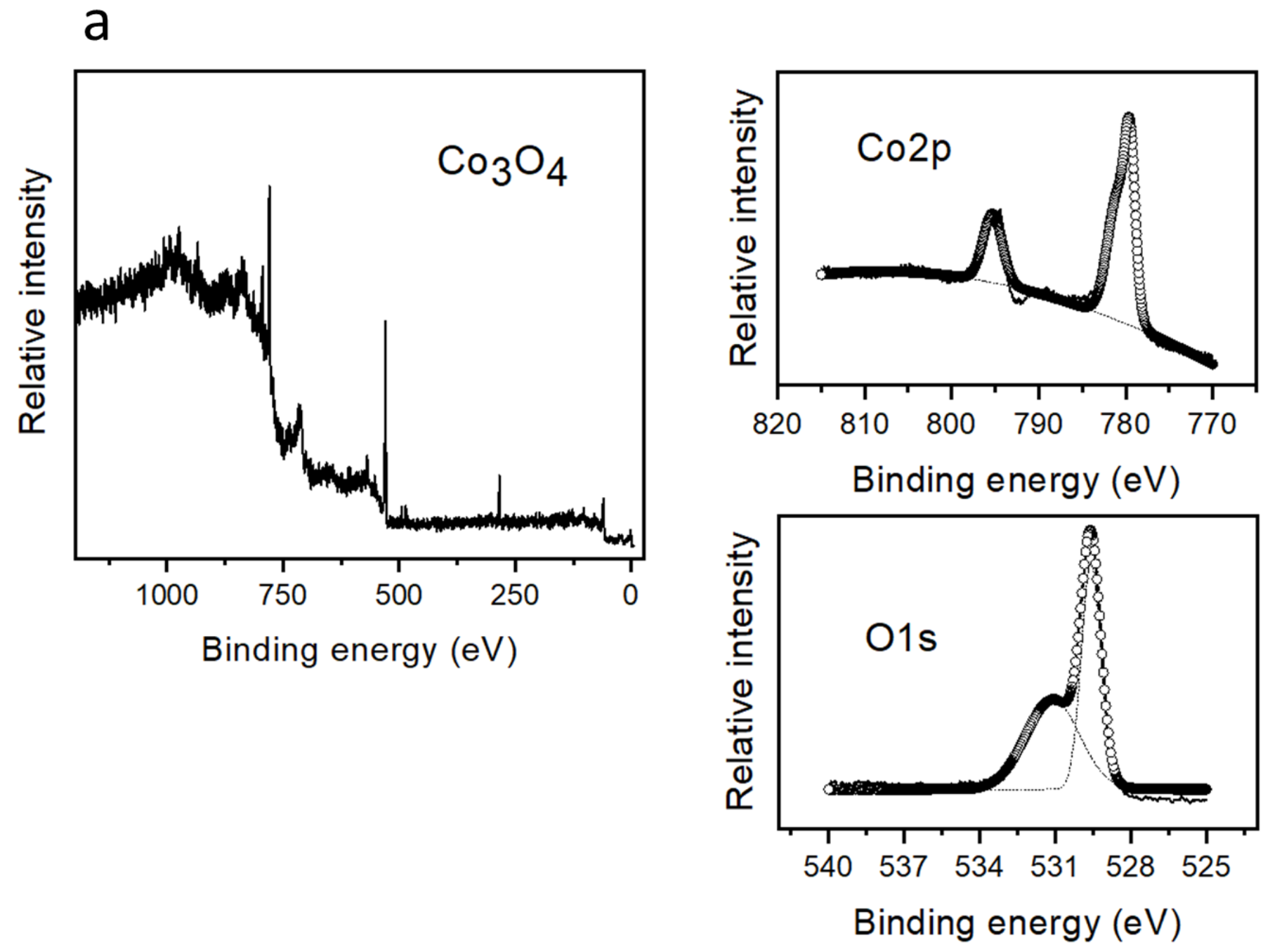

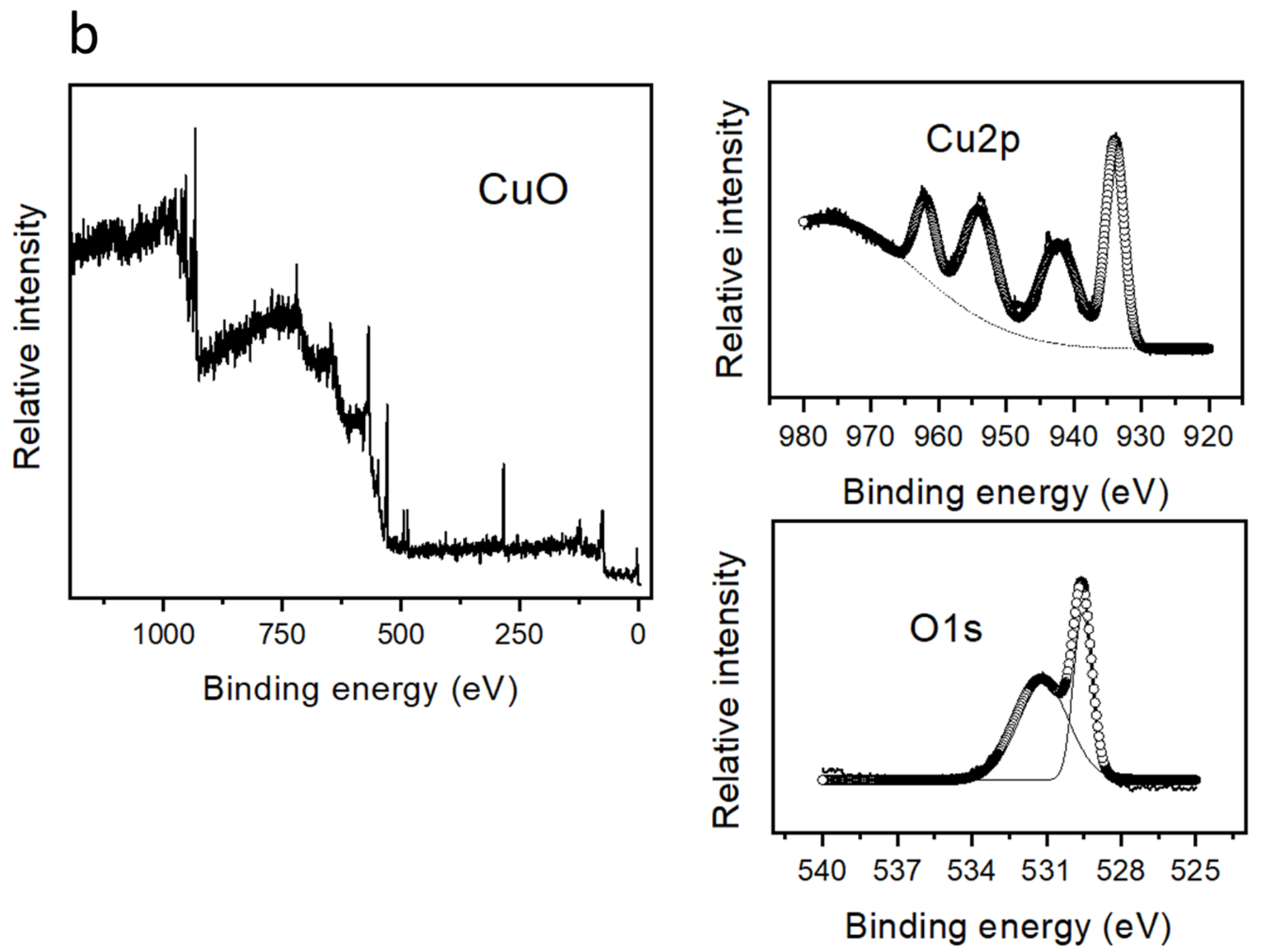
Table S1 Comparison of HER activities of the composite $\mathrm{Co}_{3} \mathrm{O}_{4} / \mathrm{CuO}$ with efficient previously reported electrocatalysts in $1 \mathrm{M} \mathrm{KOH}$

\begin{tabular}{|c|c|c|c|}
\hline Catalyst & $\begin{array}{l}\text { Tafel slope } \\
\text { mVdec }^{-1}\end{array}$ & $\begin{array}{l}\text { Overpotential } \\
\mathrm{mV} @ 10 \\
\mathrm{~mA} / \mathrm{cm} 2\end{array}$ & References \\
\hline $\mathrm{CoP} / \mathrm{CC}, 500$ & 129 & 500 & 1 \\
\hline $\mathrm{N}, \mathrm{P}-\mathrm{G}$ & 145 & 700 & 2 \\
\hline MoSx & & 540 & 3 \\
\hline Co-S/FTO & & 480 & 4 \\
\hline Co-NRCNTs & & 450 & 5 \\
\hline Co-N-C & & 270 & 6 \\
\hline $\mathrm{CoO}_{\mathrm{x}} @ \mathrm{CN}$ & & 235 & 7 \\
\hline $\mathrm{Ni}_{3} \mathrm{FeN}-\mathrm{NPs}$ & & 238 & 8 \\
\hline $\mathrm{Ni}_{2} \mathrm{P}$ on $\mathrm{Ni}$ foam & & 221 & 9 \\
\hline CoP@PNC & & 120 & 10 \\
\hline Co/CoP@NC & & 180 & 11 \\
\hline $\mathrm{Co} @ \mathrm{CNF}$ & & 196 & 12 \\
\hline $\mathrm{CoP}_{3} \mathrm{NSs} / \mathrm{CC}$ & & 121 & 13 \\
\hline CoNPs@C & & 153 & 14 \\
\hline $\mathrm{Co}_{0.9} \mathrm{~S}_{0.58} \mathrm{P}_{0.42}$ & & 141 & 15 \\
\hline $\mathrm{Co}_{3} \mathrm{O}_{4}-\mathrm{CuO}$ & 65 & $\begin{array}{l}0.288 \mathrm{~V} \text { vs RHE } \\
\text { @ } 10 \mathrm{~mA} / \mathrm{cm}^{2}\end{array}$ & This work \\
\hline
\end{tabular}

\section{References}

[1] Tian J, Liu Q, Asiri AM, Sun X. Self-supported nanoporous cobalt phosphide nanowire arrays: an efficient 3D hydrogen-evolving cathode over the wide range of $\mathrm{pH} 0-14$. J. Am. Chem. Soc., 2014, 136, 7587-7590.

[2] Zheng Y, Jiao Y, Li LH, Xing T, Chen Y, Jaroniec M, Qiao SZ. Toward Design of Synergistically Active Carbon-Based Catalysts for Electrocatalytic Hydrogen Evolution. ACS Nano, 2014, 8, 5290-5296.

[3] Merki D, Fierro S, Vrubel H, Hu X. Amorphous molybdenum sulfide films as catalysts for electrochemical hydrogen production in water. Chem. Sci., 2011, 2, 1262-1267.

[4] Sun Y, Liu C, Grauer DC, Yano J, Long JR, Yang P, Chang CJ. Electrodeposited CobaltSulfide Catalyst for Electrochemical and Photoelectrochemical Hydrogen Generation from Water. J. Am. Chem. Soc. 2013, 135, 17699-17702. 
[5] Zou X, Huang X, Goswami A, Silva R, Sathe BR, Mikmeková E, Asefa T. Cobalt-embedded nitrogen-rich carbon nanotubes efficiently catalyze hydrogen evolution reaction at all $\mathrm{pH}$ values. Angew. Chem. Int. Ed., 2014, 53, 4372-4376.

[6] Zhang L, Liu W, Dou YB, Du Z, Shao MH. The Role of Transition Metal and Nitrogen in Metal-N-C Composites for Hydrogen Evolution Reaction at Universal pHs. J. Phys. Chem. C. 2016, 120, 29047-29053.

[7] Jin H, Wang J, Su DF, Wei ZZ, Pang ZF, Wang Y. In situ Cobalt-Cobalt Oxide/N-Doped Carbon Hybrids as Superior Bifunctional Electrocatalysts for Hydrogen and Oxygen Evolution. J. Am. Chem. Soc., 2015, 137, 2688-2694.

[8] Chen Q, Wang R, Yu MH, Zeng YX, Lu FQ, Kuang XJ, Lu XH. Bifunctional Iron-Nickel Nitride Nanoparticles as Flexible and Robust Electrode for Overall Water Splitting. Electrochim. Acta, 2017, 247, 666-673.

[9] Stern LA, Feng LG, Song F, Hu XL. $\mathrm{Ni}_{2} \mathrm{P}$ as a Janus catalyst for water splitting: the oxygen evolution activity of Ni2P nanoparticles. Energy Environ. Sci., 2015, 8, 2347-2351.

[10] Zhou Z, Mahmood N, Zhang YC, Pan L, Wang L, Zhang XW, Zou JJ. CoP nanoparticles embedded in $\mathrm{P}$ and $\mathrm{N}$ co-doped carbon as efficient bifunctional electrocatalyst for water splitting. J. Energy Chem., 2017, 26, 1223-1230.

[11] Li Y, Li HX, Cao KZ, Jin T, Wang XJ, Sun HM, Ning JX, Wang YJ, Jiao LF. Electrospun three dimensional Co/CoP@nitrogen-doped carbon nanofibers network for efficient hydrogen evolution. Energy Storage Materials, 2018, 12, 44-53.

[12] Su H, Wang HH, Zhang B, Wang KX, Lin XH, Chen JS. Enriching Co nanoparticles inside carbon nanofibers via nanoscale assembly of metal-organic complexes for highly efficient hydrogen evolution. Nano Energy, 2016, 22, 79-86.

[13] Wu TL, Pi MY, Wang XD, Guo WM, Zhang DK, Chen SJ. Developing bifunctional electrocatalyst for overall water splitting using three-dimensional porous CoP3 nanospheres integrated on carbon cloth. J. Alloys Compd., 2017, 729, 203-209.

[14] Jin QY, Ren BW, Li DQ, Cui H, Wang CX. Plasma-Assisted Synthesis of Self-Supporting Porous CoNPs@C Nanosheet as Efficient and Stable Bifunctional Electrocatalysts for Overall Water Splitting. ACS Appl. Mater. Interfaces, 2017, 9, 31913-31921.

[15] Dai ZF, Geng HB, Wang J, Luo YB, Li B, Zong Y, Yang J, Guo YY, Zheng Y, Wang X, Yan QY. Hexagonal-Phase Cobalt Monophosphosulfide for Highly Efficient Overall Water Splitting. ACS Nano, 2017, 11, 11031-11040. 